Research Article

\title{
Experimental and Theoretical Investigation of the Photoelectrical Properties of Tetrabromophenol Blue- and Bromoxylenol Blue-Based Solar Cells
}

\author{
Qian Liu, ${ }^{1,2}$ Penghui Ren, ${ }^{2}$ Xiaofei Wang, ${ }^{2}$ Yuanzuo Li $\mathbb{D},{ }^{2}$ and Yanhui Yang $\mathbb{D}^{3,4}$ \\ ${ }^{1}$ Department of Applied Physics, Xi'an University of Technology, Xi'an 710054, China \\ ${ }^{2}$ College of Science, Northeast Forestry University, Harbin, Heilongjiang 150040, China \\ ${ }^{3}$ Institute of Advanced Synthesis, School of Chemistry and Molecular Engineering, Jiangsu National Synergetic Innovation Center for \\ Advanced Materials, Nanjing Tech University, Nanjing 211816, China \\ ${ }^{4}$ School of Chemical and Biomedical Engineering, Nanyang Technological University, Singapore 639798
}

Correspondence should be addressed to Yuanzuo Li; yzli@nefu.edu.cn and Yanhui Yang; Yhyang@njtech.edu.cn

Received 5 February 2018; Revised 14 April 2018; Accepted 18 April 2018; Published 22 July 2018

Academic Editor: Nageh K. Allam

Copyright (c) 2018 Qian Liu et al. This is an open access article distributed under the Creative Commons Attribution License, which permits unrestricted use, distribution, and reproduction in any medium, provided the original work is properly cited.

\begin{abstract}
Tetrabromophenol blue and Bromoxylenol blue as the sensitizers of dye-sensitized solar cells (DSSCs) are measured in experiments. In order to better understand the photoelectrical properties of the two dyes, we obtain the UV-Vis spectra, fluorescence spectra, and current-voltage characteristics. The frontier molecular orbital, energy levels, the first hyperpolarizability, the first hyperpolarizability density, and molecular electrostatic potential are calculated with density functional theory (DFT) and time-dependent DFT (TDDFT). The critical factors including the light harvesting efficiency (LHE (Tetrabromophenol blue for 0.0284 and Bromoxylenol blue for 0.0290), the driving force of electron injection $\left(\Delta G_{\text {inject }}\right), x$-axis direction dipole moment $\left(\mu_{\text {normal }}\right)$, the conduction band of edge of the semiconductor $\left(\Delta E_{\mathrm{CB}}\right)$, and the excited-state lifetime $\left.(\tau)\right)$ are computed, which have a close connection to the short-circuit current density $\left(J_{\mathrm{sc}}\right)$ and open-circuit voltage $\left(V_{\mathrm{oc}}\right)$. The results show that the $J_{\mathrm{sc}}\left(0.09 \mathrm{~mA} / \mathrm{cm}^{2}\right)$ and $V_{\mathrm{oc}}(0.39 \mathrm{~V})$ of Tetrabromophenol blue have larger values, which can be explained by a larger absolute value of $\Delta G_{\text {inject, }}$, absolute value of $\mu_{\text {normal }}, \tau$, and $\Delta E_{\mathrm{CB}}$. Therefore, Tetrabromophenol blue displays well photoelectric conversion efficiency compared with Bromoxylenol blue.
\end{abstract}

\section{Introduction}

Currently, the utilities of fossil fuels as a major energy are applied to $80 \%[1,2]$. Especially, coal is one kind of fossil fuel, which holds a $42 \%$ margin in comparison with other energy sources [3, 4]. Fossil fuels as nonrenewable will eventually dry up; therefore, scientific researches has been paid attention to exploit inexhaustible or renewable sources, such as hydroelectric, geothermal, wind, and solar power [5-8], and these sources do not release the greenhouse gases, not contributing to global warming [9].
Solar energy is one type of renewable energy, which is propitious to protect the environment $[10,11]$. And DSSCs are viewed as a kind of promising solar energy-harvesting device for generation of electricity, which have received a great deal of interest due to their low-cost and lightweight advantages [12]. Since DSSCs were reported by O'Regan and Grätzel et al. [13], most efforts have been focused on DSSCs.

Working on DSSCs has five steps [14-16]: (1) dyes can gain electrons from the ground state to an excited state by incident photons; (2) the dyes are excited by incident 
photons, and then electrons inject into the conduction band of the semiconductor; (3) the electrons are gathered in the $\mathrm{TiO}_{2}$ film, which can transfer to the outer circuit, and the electrons return to the counter electrode; (4) the dye molecules in oxidation state are deoxidized by the electrolyte in reduction; and (5) the electrolyte in oxidation state is reduced after receiving the electron at the conducting glass, accordingly, completing a cycle.

The DSSCs are made up of a nanocrystalline porous semiconductor electrode-absorbed dye, a counter electrode, and an electrolyte containing iodide and triiodide ions $[17,18]$. From the structure and principle of solar cells, it can be found that dyes are a core part of DSSCs, which are divided into organic dyes and inorganic dyes $[19,20]$. Inorganic dyes (such as pyridline and N719) are used as sensitizer in DSSCs, which can show high efficiency; however, the inorganic dyes have more expensive cost in the field of DSSCs [21]. Therefore, organic dyes as the main object have the advantages of inexpensive medium, environmental friendliness, ease in controlling their properties, and so on. Several kinds of dyes have been reported, such as coumarin [22-24], porphyrins [25, 26], phenylene [27, 28], carbazole dyes [29], and indoline dyes [30]. About the organic dyes, researchers have performed the improved experimental strategies for the rapid screening of highly efficient DSSCs. Ma et al. [31] used three novel quinoxaline-based donor- $\pi$-acceptor-type organic dyes as sensitizers for DSSCs, showing the influence of various $\pi$-conjugation structures that contain different quinoxaline derivatives on the absorption properties, electrochemical properties, and photovoltaic performances. The results show that 2,3-dioctylquinoxaline as the spacer exhibited the highest efficiency of $8.20 \%$ with a short-circuit photocurrent density of $17.83 \mathrm{~mA} \mathrm{~cm}^{-2}$, an open-circuit photovoltage of $0.71 \mathrm{~V}$, and a fill factor of 0.65 , under standard global AM 1.5G solar light condition. Freitag et al. [32] designed sensitizers (D35 and XY1) with the copper complex $\mathrm{Cu}(\mathrm{II} / \mathrm{I})(\mathrm{tmby})$ as a redox shuttle (tmby, $4,4^{\prime}, 6,6^{\prime}$-tetramethyl-2,2' -bipyridine), showing that the highest photoelectronic conversion efficiency was $28.9 \%$.

During the past decades, quantum chemistry methods had been used to reveal the relationship between structures and properties of dyes [33-37]. He et al., [34] theoretically demonstrated that the relative position of $\pi$ spacer center on DSSCs (such as a rigidified-aromatic as $\pi$-spacer or an appropriate trimming of the position) has an influence on DSSC performance. The molecular controlling mechanism of the optical and electronic properties for organic dyes and $\mathrm{Ru}$ complexes has been revealed on the basis of DFT and TD-DFT [36, 37], and results also found that there was obviously different performance between the cis and trans isomers [36]. El-Shishtawy et al. [38] used DFT/TD-DFT to study the optical electronic properties of symmetric and asymmetric squaraine dyes of SQD1-SQD4, finding that there are well energy math between dye and semiconductor, indicating possible electron injection from the excited dyes to $\mathrm{TiO}_{2}$. Theoretical calculation provides an in-depth understanding on the micromechanism behind the experiment.
Here, Tetrabromophenol blue and Bromoxylenol blue with multibranched structures are chosen as sensitizers to study the optical and electrical properties for DSSCs, which structures and mutihydroxyl are hoped to enhance the charge transfer and adsorptivity. In order to comprehend the experimental results in depth, the absorption spectra, electronic properties, and energy gaps of the two dyes are measured and computed. The UV-Vis spectra and fluorescence spectra are computed by DFT and TDDFT. In addition, the excited-state lifetime, total static first hyperpolarizability, first hyperpolarizability density, molecular electrostatic potential, and natural bond orbital of two dyes are computed via DFT, and the value of experiment and computational work provides deeply insight into the relationship between structure and performance for two DSSCs.

\section{Experimental and Computational Methods}

2.1. Experiment. Tetrabromophenol blue and Bromoxylenol blue with a purity of greater than $98.0 \%$ was obtained from Aladdin (Shanghai). Tetrabromophenol blue and Bromoxylenol blue were dissolved in ethanol solution, which were measured with TU-1900 spectrometer (Beijing, China). Solar photon-energy conversion efficiency measurements were done with a solar simulation instrument (Pecell-15, Japan), and light intensity was adjusted via a reference standard Si solar solar cell at sunlight intensity of $100 \mathrm{~mW} \mathrm{~cm}^{-2}$. Cyclic voltammetry experiments were performed using $\mathrm{CH}$ Instruments $\mathrm{CHI615E}$ Electrochemical Workstation (shanghai Chenhua Instrument Co. Ltd., Shanghai, China). The redox potentials of the dyes were measured in a tetrahydrofuran (THF) solution, using $0.1 \mathrm{M} \mathrm{KNO}_{3}$ as the supporting electrolyte. The scan range was between $-1000 \mathrm{mV}$ and $+1000 \mathrm{mV}$, and the initial scan potential was $-1000 \mathrm{mV}$ at a scan rate of $50 \mathrm{mV} / \mathrm{s}$, with a three-electrode system consisting of a glassy carbon working electrode, a platinum counter electrode, and an $\mathrm{Ag} / \mathrm{AgCl}$ reference electrode.

2.2. Computation. Ground-state structures and electronic structures of Tetrabromophenol blue and Bromoxylenol blue are optimized with DFT [39] using PBEPBE functionals [40-43] with 6-31G (d) basis set. Optimization in ethanol solution has been done with the conductor-like polarizable continuum model (CPCM) [44]. Absorption spectrums (UV-Vis) are calculated using the TD-DFT method [45-47] with PBEPBE/6-311G(d, p), which the result shows a closed trend with the experiment for small dendrimer system in comparison with calculations of B3LYP and Cam-B3LYP (see Table S1). Fluorescence spectroscopy of Tetrabromophenol blue and Bromoxylenol blue is simulated by TD-PBEPBE/6-311G(d, p) and TDCAM-B3LYP/6-311G(d, p). The polarizability and hyperpolarizability tensors $\left(\boldsymbol{\alpha}_{x x}, \boldsymbol{\alpha}_{x y}, \boldsymbol{\alpha}_{y y}, \boldsymbol{\alpha}_{x z}, \boldsymbol{\alpha}_{y z}, \boldsymbol{\alpha}_{z z}\right.$ and $\boldsymbol{\beta}_{x x x}, \boldsymbol{\beta}_{x x y}$, $\boldsymbol{\beta}_{x y y}, \boldsymbol{\beta}_{y y y}, \boldsymbol{\beta}_{x x z}, \boldsymbol{\beta}_{x y z}, \boldsymbol{\beta}_{y y z}, \boldsymbol{\beta}_{x z z}, \boldsymbol{\beta}_{y z z}, \boldsymbol{\beta}_{z z z}$ ) can be obtained by a frequency job output file of Gaussian. However, $\boldsymbol{\alpha}$ and $\beta$ values of Gaussian output are in atomic units (au). So, they have been converted into electronic units (esu) ( $\alpha$ : 


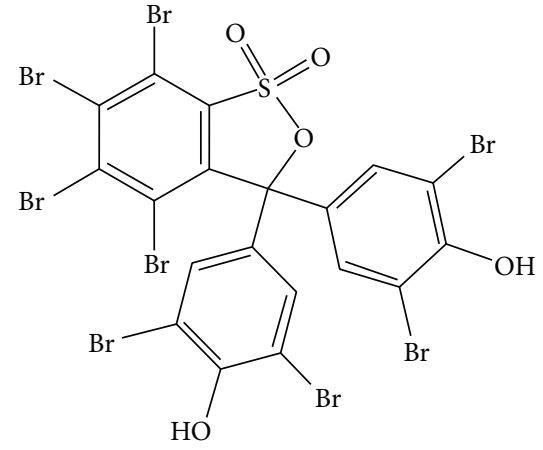

Tetrabromophenol blue

(a)<smiles>Cc1cc(C2(c3cc(C)c(O)c(Br)c3C)OS(=O)(=O)c3ccccc32)c(C)c(Br)c1O</smiles>

Bromoxylenol blue

(b)

Figure 1: Chemical structures of two molecules Tetrabromophenol blue and Bromoxylenol blue.

$1 \mathrm{au}=0.1482 \times 10^{-24}$ esu, $\beta$ : $\left.1 \mathrm{au}=8.6393 \times 10^{-33} \mathrm{esu}\right)$. The mean values of the polarizability $(\triangle \alpha)$ and the first hyperpolarizability $\beta_{\text {tot }}$ can be calculated using the following equations [48].

$$
\begin{aligned}
& \boldsymbol{\alpha}_{\mathrm{tot}}= \frac{1}{3}\left(\boldsymbol{\alpha}_{x x}+\boldsymbol{\alpha}_{y y}+\boldsymbol{\alpha}_{z z}\right) \\
& \begin{aligned}
\Delta \boldsymbol{\alpha}=\frac{1}{\sqrt{2}} & {\left[\left(\boldsymbol{\alpha}_{x x}-\boldsymbol{\alpha}_{y y}\right)^{2}+\left(\boldsymbol{\alpha}_{y y}-\boldsymbol{\alpha}_{z z}\right)^{2}\right.} \\
& +\left(\boldsymbol{\alpha}_{z z}-\boldsymbol{\alpha}_{x x}\right)^{2}+6 \boldsymbol{\alpha}_{x z}{ }^{2} \\
& \left.+6 \boldsymbol{\alpha}_{x y}{ }^{2}+6 \boldsymbol{\alpha}_{y z}{ }^{2}\right]^{1 / 2}
\end{aligned} \\
& \boldsymbol{\beta}_{\mathrm{Tol}}= \sqrt{\boldsymbol{\beta}_{x}^{2}+\boldsymbol{\beta}_{y}^{2}+\boldsymbol{\beta}_{z}^{2}} .
\end{aligned}
$$

Individual static components in the above equation are calculated from

$$
\boldsymbol{\beta}_{i}=\boldsymbol{\beta}_{i i i}+\frac{1}{3} \sum_{i \neq j}\left(\boldsymbol{\beta}_{i j j}+\boldsymbol{\beta}_{j i j}+\boldsymbol{\beta}_{j j i}\right),
$$

where $\boldsymbol{\beta}_{i j k}(i, j, k=x, y, z)$ are tensor components of hyperpolarizability. Due to the Kleinman symmetry, the equation was obtained [49]:

$$
\begin{aligned}
\boldsymbol{\beta}_{\mathrm{tot}}= & {\left[\left(\boldsymbol{\beta}_{x x x}+\boldsymbol{\beta}_{x y y}+\boldsymbol{\beta}_{x z z}\right)^{2}+\left(\boldsymbol{\beta}_{y y y}+\boldsymbol{\beta}_{y z z}+\boldsymbol{\beta}_{y x x}\right)^{2}\right.} \\
& \left.+\left(\boldsymbol{\beta}_{z z z}+\boldsymbol{\beta}_{z x x}+\boldsymbol{\beta}_{z y y}\right)^{2}\right]^{1 / 2}
\end{aligned}
$$

All the quantum chemical computations are performed by using Gaussian 09 package [50]. Multiwfn 3.39 was applied for wave function analyses [51].

\section{Results and Discussion}

3.1. The Optical Properties of the Dye. The chemical structures of the two dyes (Tetrabromophenol blue and Bromoxylenol blue) are shown in Figure 1. Figure 2(a) showed the experimental absorption spectra of the two dyes in ethanol, and the data of the absorption peaks are summarized in Table S1. As shown in Figure 2(a), Tetrabromophenol blue and Bromoxylenol blue only have one absorption peak at $400 \mathrm{~nm} \sim 450 \mathrm{~nm}$, at which the maximum absorption peaks $\left(\lambda_{\max }\right)$ of Tetrabromophenol blue and Bromoxylenol blue are $433 \mathrm{~nm}$ and $426 \mathrm{~nm}$, respectively.

In addition, the optical properties of Tetrabromophenol blue and Bromoxylenol blue are computed via TD-DFT/ PBEPBE/6-311G(d, p) in gas and solvent and the absorption spectra of two dyes are displayed in Figures 2(b) and 2(c). The absorption peaks and oscillator strengths were investigated, which were listed in Table S1. The absorption region of Tetrabromophenol blue is $300 \mathrm{~nm}-550 \mathrm{~nm}$, and the absorption region of Bromoxylenol blue is $275 \mathrm{~nm}-500 \mathrm{~nm}$. About the photovoltaic performance, oscillator strength is an important factor and they can be seen from Table S1. For gas (see Figure 2(b)), the strongest oscillator strength of Tetrabromophenol blue is the excited state S2, and the oscillator strength is 0.0072 . The electron transition of Tetrabromophenol blue is from $\mathrm{H}-1 \rightarrow \mathrm{L}$, and the excited states $\mathrm{S} 1$ and $\mathrm{S} 3$ are from $\mathrm{H} \rightarrow \mathrm{L}$ and $\mathrm{H} \rightarrow \mathrm{L}+1$, respectively. The largest oscillator strength of Bromoxylenol blue is 0.0092 (for S1), and electrons transferring are from $\mathrm{H} \rightarrow \mathrm{L}$, and the excited states $\mathrm{S} 2$ and $\mathrm{S} 3$ are from $\mathrm{H} \rightarrow \mathrm{L}+1$ and $\mathrm{H}-1 \rightarrow \mathrm{L}+1$, respectively. For solvent (see Figure 2(c)), the absorption region of Tetrabromophenol blue is $200 \mathrm{~nm}-$ $550 \mathrm{~nm}$. The absorption region of Bromoxylenol blue is $270 \mathrm{~nm}-475 \mathrm{~nm}$. The absorption peak for Bromoxylenol blue is smaller than that of Tetrabromophenol blue, reflecting the trend of the experiment. There is also difference between calculation and experiment probably because the single molecule was considered in calculation, which can not completely respond to experimental conditions. The optical performance and oscillator strength of the dye are showed in Table S1. The third excited state S3 of Tetrabromophenol blue has the strongest oscillator strength, and the electron transition of Tetrabromophenol blue is from $\mathrm{H} \rightarrow \mathrm{L}+1$. The strongest oscillator strength of Bromoxylenol blue is the first excited state $\mathrm{S} 1$ (0.0128), and electrons transferring are from $\mathrm{H} \rightarrow \mathrm{L}$. 


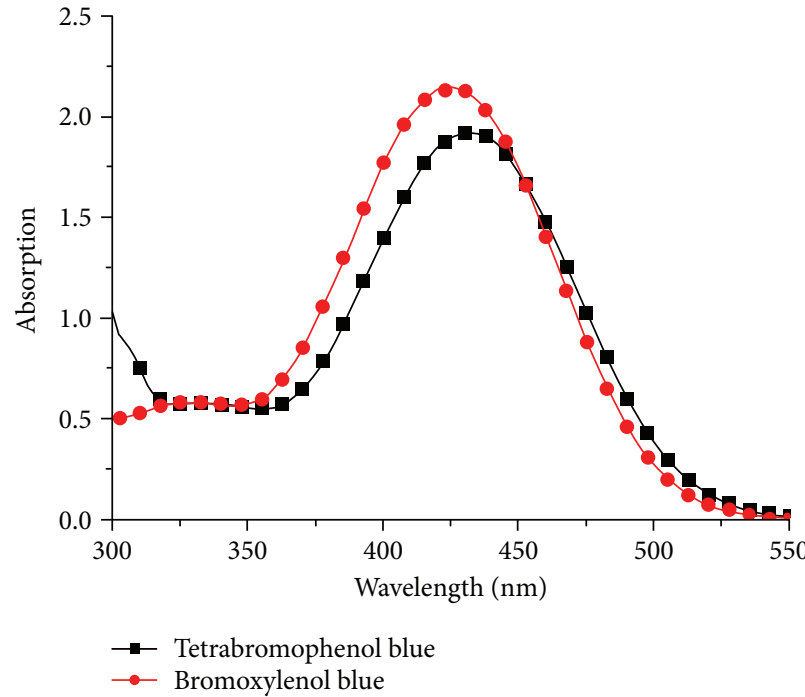

(a)

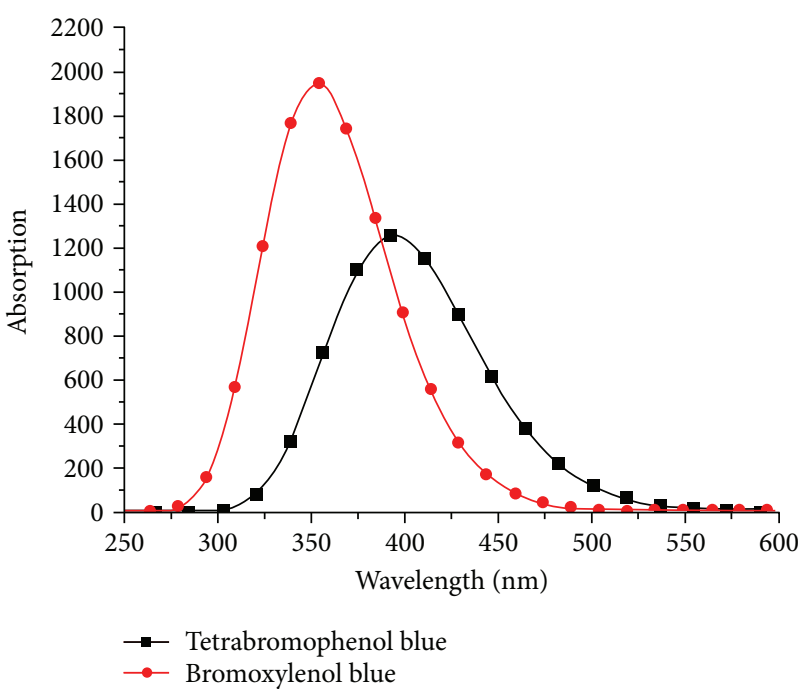

(b)

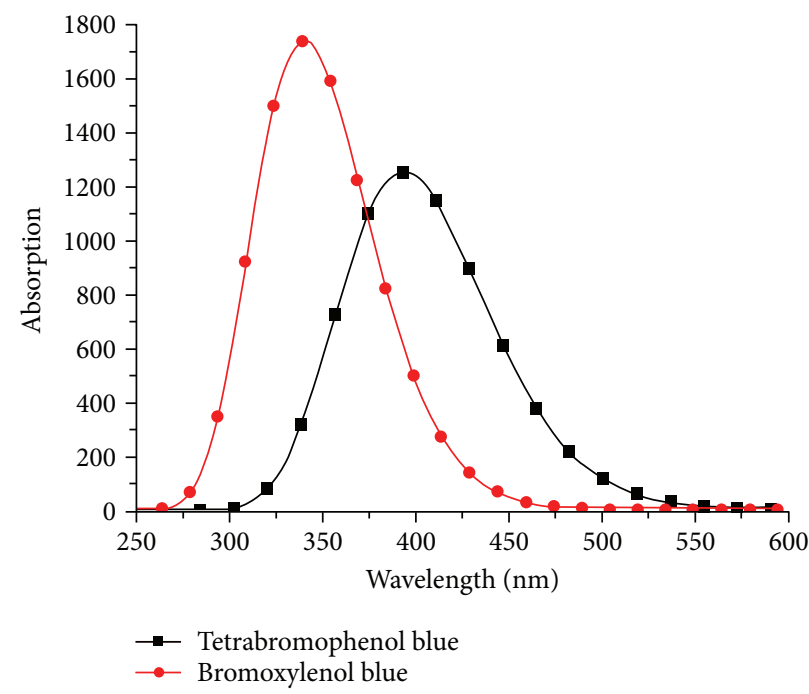

(c)

FIgURE 2: The experimental UV-Vis spectrum of Tetrabromophenol blue and Bromoxylenol blue in ethanol (a); the theoretical UV-Vis spectrum of Tetrabromophenol blue and Bromoxylenol blue by TDDFT/PBEPBE/6-31G(d) basis set in gas (b) and ethanol (c).

Moreover, the selected frontier molecular orbitals of the two dyes are shown in Figure 3. Tetrabromophenol blue has three parts, which are sulfonic acid, 1,2,3,4-tetrabromobenzene, and 2,6-dibromophenol. For S2 (HOMO-1LUMO), electron density of HOMO-1 level centers on two 2,6-dibromophenol groups, which transmits to the sulfonic acid and 1,2,3,4-tetrabromobenzen (LUMO level). Electron density of HOMO level is focused on 2,6-dibromophenol groups that it transits to sulfonic acid and 1,2,3,4-tetrabromobenzen at S1. For S3 (HOMO-LUMO+1), electron density of HOMO level transmits to sulfonic acid and 1,2,3,4tetrabromobenzen (LUMO+1 level) in gas. For solvent, electron densities of HOMO level and LUMO+1 level are transmitted between two 2,-dibromophenol groups at S1. For S3, electron density in 2,6-dibromophenol groups was moved to sulfonic acid and 1,2,3,4-tetrabromobenzen (LUMO+1 level). For S3 (HOMO-1-LUMO), electron density of HOMO-1 level is focused on two 2,6-dibromophenol groups, and it was transferred to sulfonic acid and 1,2,3,4-tetrabromobenzen. Bromoxylenol blue has three parts, which are 2bromo-3,6-dim ethylphenol, sulfonic acid, and benzene ring. For S1 (HOMO-LUMO), electron density of HOMO level is focused on two 2-bromo-3,6-dim ethylphenol groups, which transits to sulfonic acid and benzene ring (LUMO level) in gas. For S2 (HOMO-LUMO+1), electron density of HOMO level is focused on a 2-bromo-3,6-dim ethylphenol group, which was moved to sulfonic acid and benzene ring (LUMO+1 level). For S3, electron density is from HOMO-1 to $\mathrm{LUMO}+1$ level. For solvent, electron density of HOMO level is focused on a 2-bromo-3,6-dim ethylphenol group that it transmits to the other 2-bromo-3,6-dim ethylphenol group (LUMO level) for S1. For S3 (HOMO-1), electron 


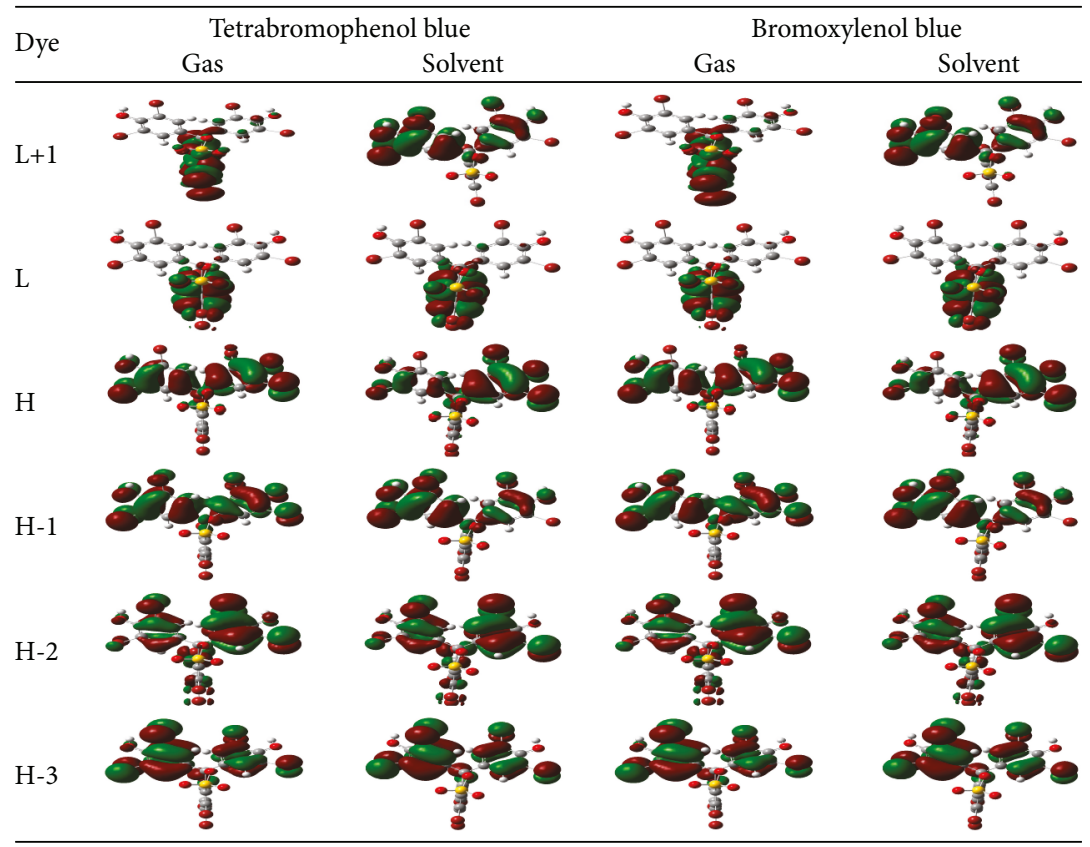

Figure 3: Electron densities of the selected HOMO and LUMO of the Tetrabromophenol blue and Bromoxylenol blue in gas and solvent.

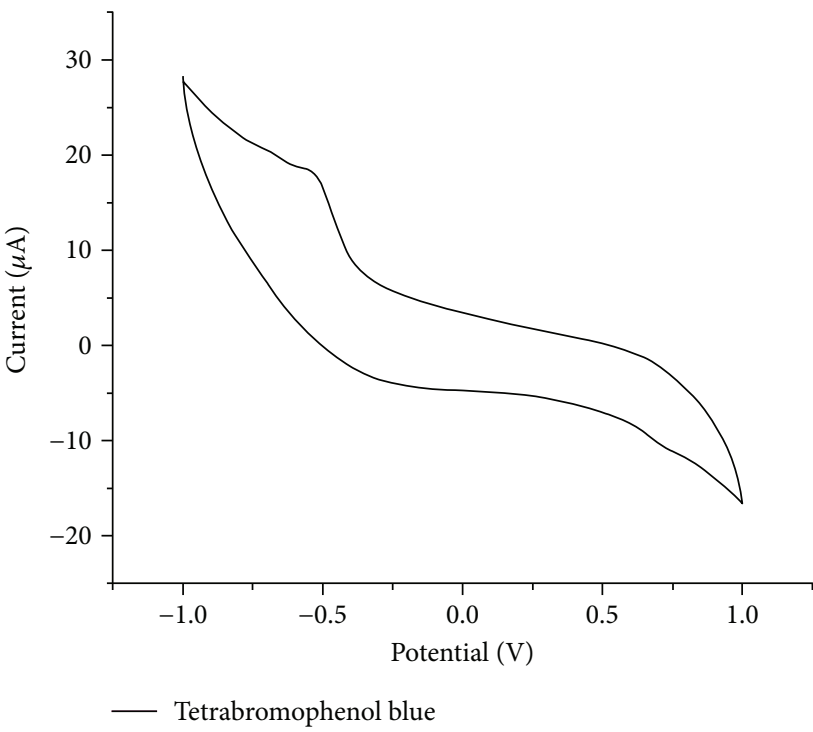

(a)

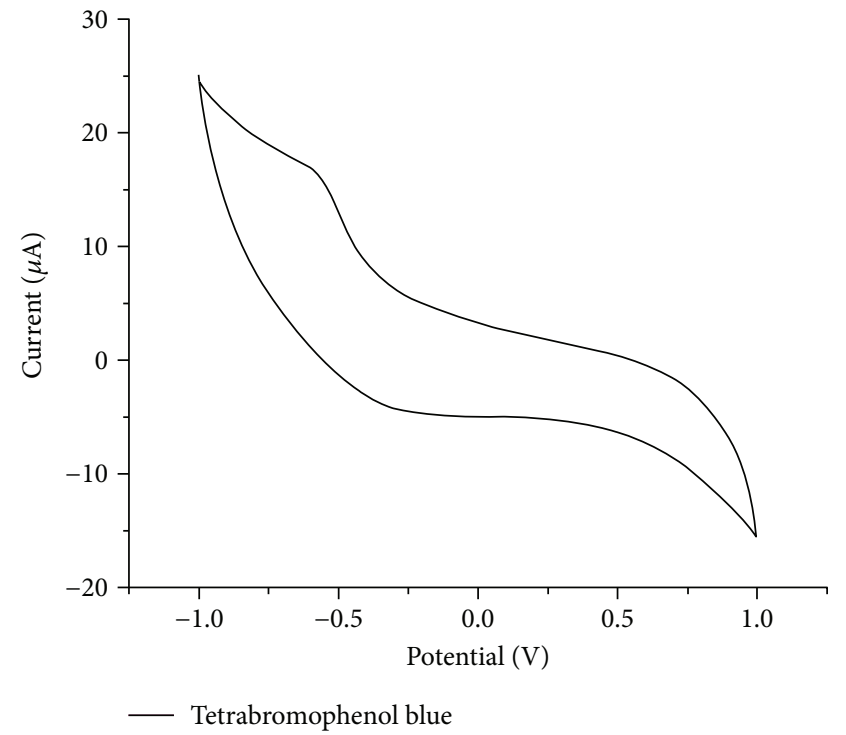

(b)

FIgURE 4: Cyclic voltammograms of (a) Tetrabromophenol blue and (b) Bromoxylenol blue.

density of HOMO-1 level is focused on two 2-bromo-3,6dim ethylphenol groups, which transmits to a 2-bromo-3,6dim ethylphenol group (LUMO level). For S3 (HOMOLUMO+1), electron density of HOMO level transmits to sulfonic acid and benzene ring (LUMO+1).

3.2. Electrochemical Characteristic. The characteristics of electron transition are from an excited state to the conduction band of the semiconductor, and it can be achieved from the investigation of electrochemical properties. The electrochemical characteristics of Tetrabromophenol blue and
Bromoxylenol blue are measured by cyclic voltammetry measurements in ethanol solvent, and the supporting electrolyte is $\mathrm{KNO}_{3}$ [52], and the results are listed in Figures 4(a) and 4 (b), showing that the onset oxidation potentials are $0.41 \mathrm{eV}$ and $-0.32 \mathrm{eV}$ for Tetrabromophenol blue and $0.55 \mathrm{eV}$ and $-0.38 \mathrm{eV}$ for Bromoxylenol blue, and they are obtained by the intersection of two tangent lines for the rising current curve and the starting current curve. The HOMO and LUMO energy corresponds to the onset oxidation potential of Tetrabromophenol blue and Bromoxylenol blue. While the working electrode is glassy carbon electrode, the 


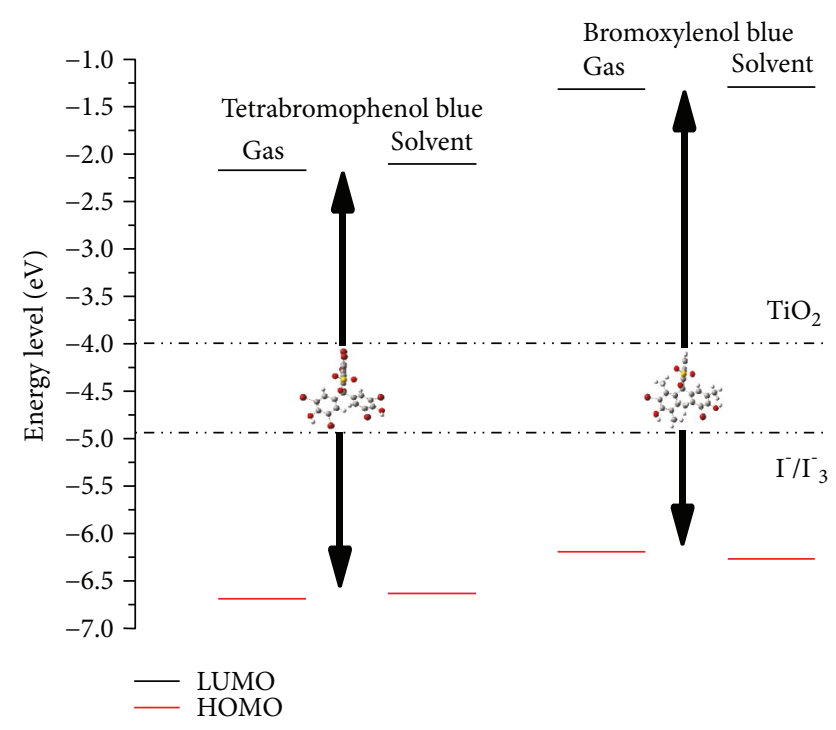

Figure 5: Calculated HOMOs, LUMOs, and energy gaps of Tetrabromophenol blue and Bromoxylenol blue.

reference electrode is saturated calomel electrode. So, the HOMO energy and LUMO energy can be calculated according to the equation reported by de Leeuw et al. [53]: $E_{\mathrm{HOMO}}=-\left(E_{\mathrm{OX}}+4.40 \mathrm{eV}\right)$ and $E_{\mathrm{LUMO}}=-\left(E_{\mathrm{Red}}+4.40 \mathrm{eV}\right)$, where $E_{\mathrm{OX}}$ and $E_{\mathrm{Red}}$ represent the onset oxidation potential of Tetrabromophenol blue and Bromoxylenol blue. Therefore, the HOMO energy and LUMO energy of Tetrabromophenol blue are $-4.81 \mathrm{eV}$ and $-4.08 \mathrm{eV}$, respectively, and those of Bromoxylenol blue are $-4.90 \mathrm{eV}$ and $-4.02 \mathrm{eV}$, respectively. In general, the energy gap $\left(E_{\mathrm{g}}\right)$ of Tetrabromophenol blue is smaller than that of Bromoxylenol blue. In view of those, Tetrabromophenol blue has the greater donating electron ability.

In order to gain a better understanding of experimental values, the HOMOs, LUMOs, and energy gaps of Tetrabromophenol blue and Bromoxylenol blue are compared in the gas and solvent phases (see Figure 5), and the data are listed in Table S2. Dyes have smaller energy gaps, which means that dyes are easier excited. Energy levels of $\mathrm{TiO}_{2}$ and electrolyte $\left(\mathrm{I}^{-} / \mathrm{I}_{3}^{-}\right)$are shown in Figure 5, and the LUMO energy is higher than those of $\mathrm{TiO}_{2}$ $(-4 \mathrm{eV})$, and the HOMO energy is lower than those of $\mathrm{I}^{-} / \mathrm{I}^{-}{ }_{3}(-4.8 \mathrm{eV})$ [54]. For Tetrabromophenol blue, the HOMO levels of gas and solvent are $-6.69 \mathrm{eV}$ and $-6.64 \mathrm{eV}$, respectively, and the LUMO levels are $-2.17 \mathrm{eV}$ and $-2.10 \mathrm{eV}$, respectively. The HOMO levels and LUMO levels of Bromoxylenol blue are computed, and the results are $-6.20 \mathrm{eV},-6.27 \mathrm{eV},-1.32 \mathrm{eV}$, and $-1.29 \mathrm{eV}$. The data show that the energy gap of Tetrabromophenol blue is smaller than that of Bromoxylenol blue, which means that Tetrabromophenol blue is easier excited.

3.3. Polarizability and First Hyperpolarizability Calculations. The dipole moment $(\mu)$, linear polarizability $(\boldsymbol{\alpha})$, anisotropy of the polarizability $(\Delta \boldsymbol{\alpha})$, and first hyperpolarizability $(\boldsymbol{\beta})$ are important factors of nonlinear optical (NLO)
TABLE 1: The dipole moments $\mu$ (D), the polarizability $\boldsymbol{\alpha}(\mathrm{au})$, the average polarizability $\boldsymbol{\alpha}_{\text {tot }}$ (esu), the anisotropy of the polarizability $\Delta \boldsymbol{\alpha}$ (esu), and the first hyperpolarizability $\boldsymbol{\beta}_{\mathrm{tot}}$ (esu) of Tetrabromophenol blue and Bromoxylenol blue.

\begin{tabular}{lccc}
\hline \multicolumn{2}{c}{ Tetrabromophenol blue } & \multicolumn{2}{c}{ Bromoxylenol blue } \\
\hline$\mu_{x}=-1.3838$ & $\boldsymbol{\beta}_{x x x}=166.279$ & $\mu_{x}=-0.6012$ & $\boldsymbol{\beta}_{x x x}=135.324$ \\
$\mu_{y}=0.6285$ & $\boldsymbol{\beta}_{x x y}=-74.417$ & $\mu_{y}=-0.0071$ & $\boldsymbol{\beta}_{x x y}=325.867$ \\
$\mu_{z}=3.6474$ & $\boldsymbol{\beta}_{x y y}=325.971$ & $\mu_{z}=9.0028$ & $\boldsymbol{\beta}_{x y y}=-91.592$ \\
$\mu_{\text {tot }}=3.9514$ & $\boldsymbol{\beta}_{y y y}=-291.467$ & $\mu_{\text {tot }}=9.0229$ & $\boldsymbol{\beta}_{y y y}=405.071$ \\
$\boldsymbol{\alpha}_{x x}=440.475$ & $\boldsymbol{\beta}_{x x z}=38.380$ & $\boldsymbol{\alpha}_{x x}=336.744$ & $\boldsymbol{\beta}_{x x z}=38.166$ \\
$\boldsymbol{\alpha}_{x y}=4.858$ & $\boldsymbol{\beta}_{x y z}=-57.081$ & $\boldsymbol{\alpha}_{x y}=8.223$ & $\boldsymbol{\beta}_{x y z}=63.245$ \\
$\boldsymbol{\alpha}_{y y}=354.282$ & $\boldsymbol{\beta}_{y y z}=58.637$ & $\boldsymbol{\alpha}_{y y}=6.803$ & $\boldsymbol{\beta}_{y y z}=98.242$ \\
$\boldsymbol{\alpha}_{x z}=10.068$ & $\boldsymbol{\beta}_{x z z}=-69.811$ & $\boldsymbol{a}_{x z}=-14.491$ & $\boldsymbol{\beta}_{x z z}=-11.785$ \\
$\boldsymbol{\alpha}_{y z}=4.041$ & $\boldsymbol{\beta}_{y z z}=30.701$ & $\boldsymbol{\alpha}_{y z}=6.545$ & $\boldsymbol{\beta}_{y z z}=44.779$ \\
$\boldsymbol{\alpha}_{z z}=350.652$ & $\boldsymbol{\beta}_{z z z}=38.947$ & $\boldsymbol{\alpha}_{z z}=263.435$ & $\boldsymbol{\beta}_{z z z}=207.694$ \\
$\boldsymbol{\alpha}_{\text {tot }}=381.803$ & $\boldsymbol{\beta}_{\text {tot }}=556.137$ & $\boldsymbol{\alpha}_{\text {tot }}=202.327$ & $\boldsymbol{\beta}_{\text {tot }}=549.022$ \\
$\Delta \boldsymbol{\alpha}=90.45$ & & $\Delta \boldsymbol{\alpha}=300.124$ \\
\hline
\end{tabular}

properties, and $\beta$ is defined as the third derivative of the total energy. The data of $\mu, \boldsymbol{\alpha}, \Delta \boldsymbol{\alpha}$, and $\boldsymbol{\beta}$ are calculated, and the results are listed in Table 1 . The parameters of dipole moment $\left[\mu_{i}(i=x, y, z)\right.$ and total dipole moment $\left.\mu_{\text {tot }}\right]$ are showed in Table 1 , and the total dipole can be expressed [49]:

$$
\mu_{\mathrm{tot}}=\left(\mu_{x}^{2}+\mu_{y}^{2}+\mu_{z}^{2}\right)^{1 / 2} .
$$

Due to the important application of dipole moment in the research of polarizability and the first hyperpolarizability, the $\mu$ of Tetrabromophenol blue and Bromoxylenol blue is calculated to be $3.9514 \mathrm{D}$ and $9.0229 \mathrm{D}$, respectively, and $\mu_{x}$ is the dipole moment component perpendicular to the direction $\mathrm{TiO}_{2}$ surface, and they are $1.3838 \mathrm{D}$ and $0.6012 \mathrm{D}$, respectively. The $\boldsymbol{\beta}$ values are $556.137 \times 10^{-30}$ esu and $549.022 \times 10^{-30}$ esu, respectively. The $\mu, \boldsymbol{\alpha}, \Delta \boldsymbol{\alpha}$, and $\boldsymbol{\beta}$ of Tetrabromophenol blue and Bromoxylenol blue can affect the effective electron injection from the dye molecule to the conduction band of the semiconductor.

3.4. Analysis of the First Hyperpolarizability Density. In order to more deeply understand the result of hyperpolarizability, which is studied by hyperpolarizability density analysis and is a powerful technique to characterize contribution to hyperpolarizability from various molecular regions, the electron density of a system $\rho(r, F)$ may be expressed as Taylor expansion with respect to the externally applied electric field $F[55,56]:$

$$
\begin{aligned}
\rho(r, F)= & \rho^{(0)}(r)+\sum_{j} \rho_{j}^{(1)}(r) F_{j}+\frac{1}{2 !} \sum_{j} \sum_{k} \rho_{j k}^{(2)}(r) F_{j} F_{k} \\
& +\frac{1}{3 !} \sum_{j} \sum_{k} \sum_{i} \rho_{j k i}^{(3)}(r) F_{j} F_{k} F_{i}+\ldots .
\end{aligned}
$$




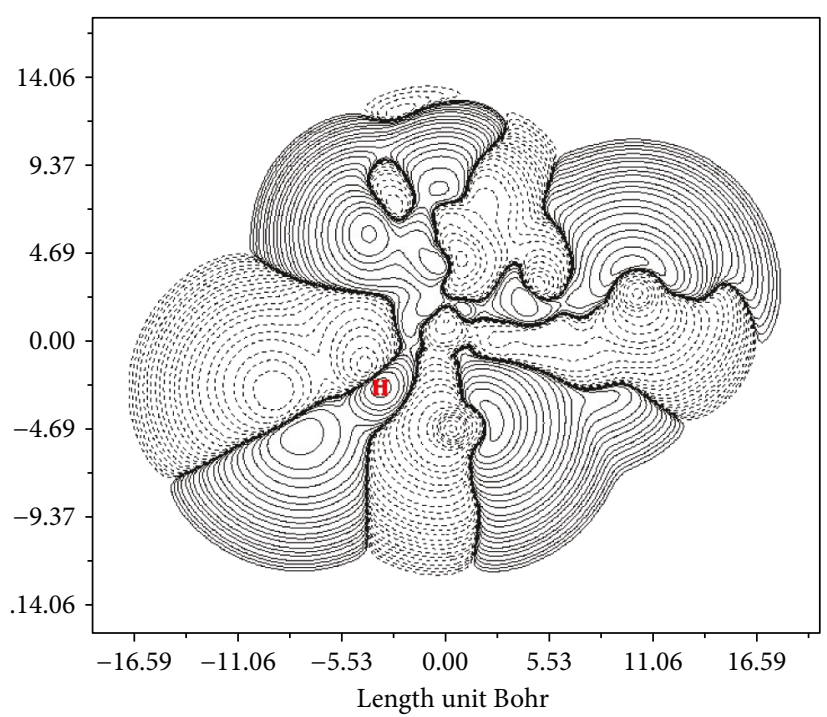

(a)

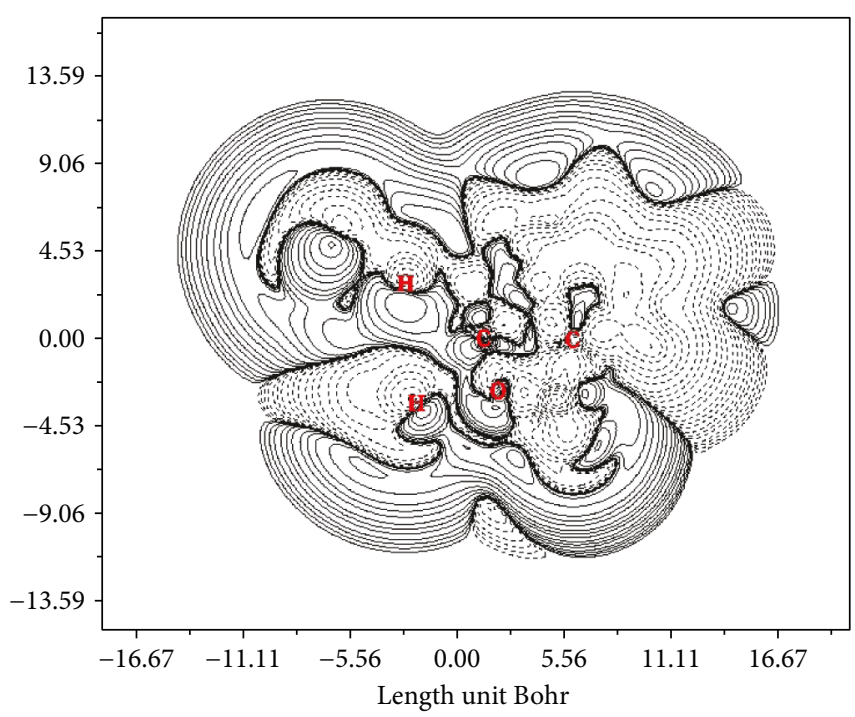

(b)

FIGURE 6: Contour maps of integrand of $\boldsymbol{\beta}_{Z Z Z}$, namely, $\rho_{Z Z}^{(2)}(r)$ on the $Z$ plane. (a) Tetrabromophenol blue; (b) Bromoxylenol blue. Solid and dash lines correspond to positive and negative parts, respectively.

From the above equation and expansion formula of dipole in the power of $F$, a component of the first hyperpolarizability can be expressed:

$$
\boldsymbol{\beta}_{i j k}=-\frac{1}{2 !} \int r_{i} \rho_{j k}^{(2)}(r) d r,
$$

where the first hyperpolarizability density is defined as

$$
\rho_{j k}^{(2)}(r)=\left.\frac{\partial^{2} \rho(r)}{\partial F_{j} \partial F_{k}}\right|_{F=0} .
$$

The first hyperpolarizability is componential by ZZZ, which is the most remarkable component of $\boldsymbol{\beta}_{\text {tot }}$. According to the finite difference technique, the first hyperpolarizability density can be achieved by means of electron densities yielded under different manually applied electric fields:

$$
\rho_{Z Z}^{(2)}(r)=\frac{\left[\rho\left(r, F_{Z}\right)+\rho\left(r,-F_{Z}\right)-\rho(r, 0)\right]}{\left(F_{Z}\right)^{2}} .
$$

Here, $\rho_{Z Z}^{(2)}(r)$ is the electron density at a spatial point $r$ in the presence of a very weak electric field $F_{Z}$, which is a step size of finite difference (chosen to be $0.003 \mathrm{au}$ ). The first hyperpolarizability can be achieved from the integrand of $Z Z Z$, namely, $\rho_{Z Z}^{(2)}(r)$ of various systems presented in Figure 6. Solid and dash lines correspond to positive and negative parts, respectively, and the positive and negative regions have an important influence on nonlinear optical (NLO).

3.5. Molecular Electrostatic Potential. For molecular electrostatic potentials (MEP) about the nuclear and charge distribution of Tetrabromophenol blue and Bromoxylenol blue, they are viewed as a tool for interpretation and prediction of chemical reactivity and a plot of the MEP of a chemical species is helpful in understanding its reactive behavior [57]. The MEP maps of Tetrabromophenol blue and Bromoxylenol blue are shown in Figure 7. The electron-rich (negative) region, electron-poor (positive) region, and zero electrostatic potential are denoted in red color, blue color, and green color, respectively, which means that electrophilic attack appears in the negative region and nucleophilic reactions happen on the positive region. So, the electron concentrations are shown by different colors, and the values of electron density $(V(r))$ increase in the following order [58]: red $>$ yellow $>$ green $>$ blue.

The $(V(r))$ range of Tetrabromophenol blue and Bromoxylenol blue is from -0.06 au (deepest red) to 0.06 au (deepest blue) in MEP. Electrophilic attack and nucleophilic reactions of Tetrabromophenol blue and Bromoxylenol blue happen on oxygen atoms and hydrogen atoms, which are $-\mathrm{SO}_{3}$ and $-\mathrm{OH}$, respectively. Moreover, MEP is also shown that two dyes display the redistribution of electron density with the positive region and negative region, which are identified with the transfer of electron density.

3.6. Photovoltaic Characterization of Dyes. Efficiency as an important factor is an important criterion for solar cells. Moreover, it has a close relationship with the spectra and intensity of the incident sunlight. The photo-toelectric conversion efficiency $(\eta)$ is obtained by the shortcircuit density $\left(J_{\mathrm{sc}}\right)$, open-circuit voltage $\left(V_{\mathrm{oc}}\right)$, and fill factor $(\mathrm{FF})$. The $\eta$ is equal to these three factors than the incident solar power $\left(P_{\text {inc }}\right)$ demonstrated as the following equation [59]:

$$
\eta=\frac{V_{\mathrm{oc}} J_{\mathrm{sc}} \mathrm{FF}}{P_{\text {inc }}} .
$$




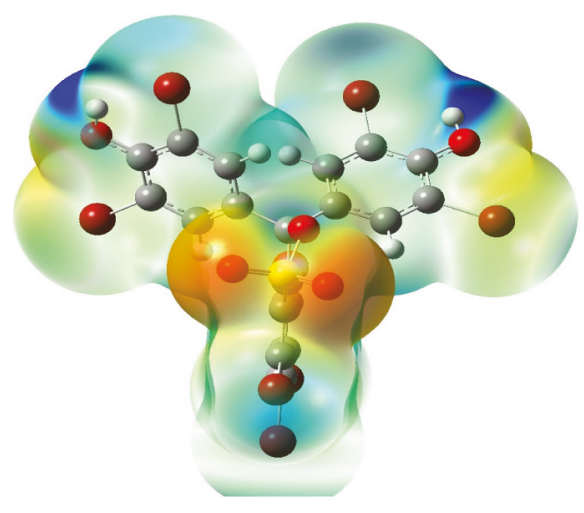

Tetrabromophenol blue

(a)

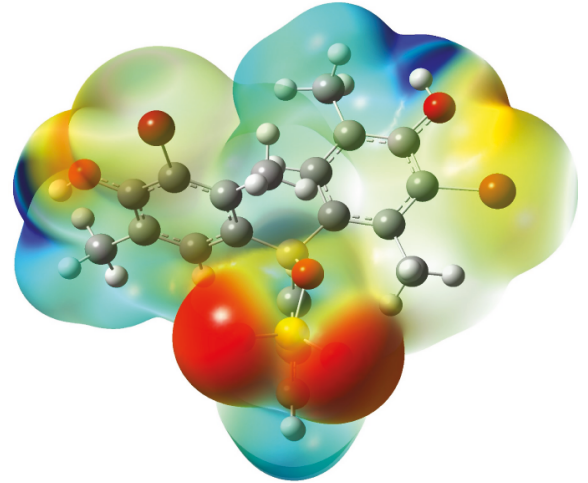

Bromoxylenol blue

(b)

Figure 7: Molecular electrostatic potential map calculated at the DFT/6-31G(d) level (Tetrabromophenol blue and Bromoxylenol blue).

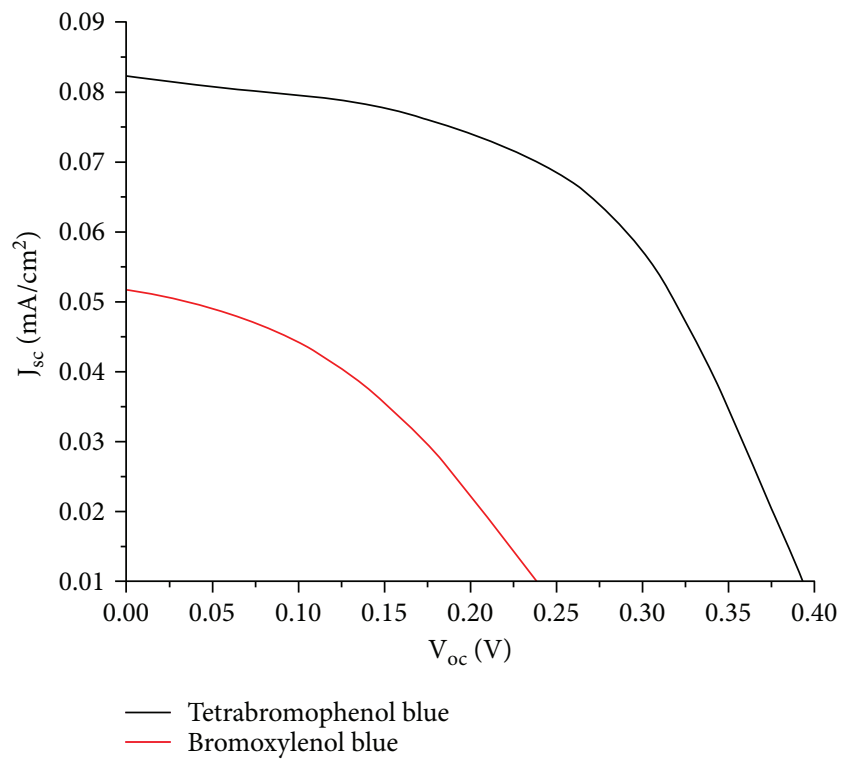

FIGURE 8: The photocurrent-potential $(I-V)$ characteristics of the DSSCs with $\mathrm{TiO}_{2}$ film electrode sensitized by Tetrabromophenol blue and Bromoxylenol blue.

FF is defined as the ratio of the maximum power obtained from the DSSC and the theoretical maximum power, which is formulated as [60]

$$
\mathrm{FF}=\frac{I_{\mathrm{m}} V_{\mathrm{m}}}{J_{\mathrm{sc}} V_{\mathrm{oc}}}
$$

Here, $I_{\mathrm{m}}$ and $V_{\mathrm{m}}$ were the current and voltage, respectively, related to the maximum power. For experiment, Tetrabromophenol blue and Bromoxylenol blue are measured with the current-voltage $(I-V)$ instrument under sunlight intensity of $100 \mathrm{~mW} \mathrm{~cm}^{-2}$, and they are shown in Figure 8, and the photoelectrochemical parameters of DSSCs are given in Table S3. Comparing the photovoltaic characteristics of the DSSCs between Tetrabromophenol blue and Bromoxylenol blue, photoelectric conversion efficiency of Tetrabromophenol blue is higher $(0.02 \%)$, with $V_{\mathrm{oc}}$ of $0.39 \mathrm{~V}, J_{\mathrm{sc}}$ of $0.09 \mathrm{~mA} \mathrm{~cm}^{-2}$, and FF of 0.59.

3.7. Theoretical Analysis for $J_{s c}$ and $V_{o c}$. According to (9), $J_{s c}$, $V_{\mathrm{oc}}$, and FF play a decisive role for photoelectric conversion efficiency. Theoretical analyses for $J_{\mathrm{sc}}$ and $V_{\mathrm{oc}}$ are computed as follows [61]:

$$
V_{\mathrm{oc}}=\frac{E_{\mathrm{CB}}+\Delta E_{\mathrm{CB}}}{q}+\frac{K T}{q} \ln \left(\frac{n_{\mathrm{c}}}{N_{\mathrm{CB}}}\right)-\frac{E_{\text {redox }}}{q} .
$$

Here, $E_{\mathrm{CB}}$ is the conduction band edge of the semiconductor substrate, $\Delta E_{\mathrm{CB}}$ is the shift of $E_{\mathrm{CB}}, q$ is the unit charge, $K$ is the Boltzmann constant, $T$ is the absolute temperature, $n_{c}$ is the number of electrons in the conduction band, $N_{\mathrm{CB}}$ is the density of accessible states in the conduction band and $E_{\text {redox }}$ is the reduction-oxidation potential of the electrolyte. While in DSSCs, $V_{\mathrm{oc}}$ is closely related with $\Delta E_{\mathrm{CB}}$ and $\Delta E_{\mathrm{CB}}[62]:$

$$
\Delta E_{\mathrm{CB}}=\frac{-q \mu_{\text {normal }} \gamma}{\varepsilon_{0} \varepsilon} .
$$

Here, $\gamma$ is adsorbed on the surface concentration and $\mu_{\text {normal }}$ is the dipole moment component perpendicular to the direction $\mathrm{TiO}_{2}$ surface (where the $\mu_{\text {normal }}$ was the $x$-axis direction), $\varepsilon_{0}$ is the gas permittivity, and $\varepsilon$ is the dielectric constant of the organic monolayer. Based on (12), the values of $\mu_{\text {normal }}$ and $\Delta E_{\mathrm{CB}}$ have proportional relationship. $\mu_{\text {normal }}$ values of Tetrabromophenol blue and Bromoxylenol blue are $-1.3838 \mathrm{D}$ and $-0.6012 \mathrm{D}$ (see Table 1), respectively. The absolute value of $\mu_{\text {normal }}$ of Tetrabromophenol blue is larger than that of Bromoxylenol blue. According to (11) and (12), $\mu_{\text {normal }}$ is directly proportional to $V_{\mathrm{oc}}$.

$J_{\mathrm{sc}}$ in DSSCs is determined by the following equation [63]:

$$
J_{\text {sc }}=\int \operatorname{LHE}(\lambda) \cdot \Delta G_{\text {inject }} d \lambda .
$$

This equation includes two important factors that have direct influence on DSSCs $\eta$, LHE, and $\Delta G_{\text {inject }}$. LHE is light harvesting efficiency and $\Delta G_{\text {inject }}$ is injection efficiency of the 
TABLE 2: The driving force of electron injection $\Delta G_{\text {inject }}$ (in eV) for the Tetrabromophenol blue and Bromoxylenol blue in the solvent.

\begin{tabular}{lccc}
\hline Dye & $E_{\text {OX }}^{\text {dye }}$ & $E_{\text {OX }}^{\text {dye }^{*}}$ & $\Delta G_{\text {inject }}$ \\
\hline Tetrabromophenol blue & 4.81 & 1.95 & -2.25 \\
Bromoxylenol blue & 4.90 & 1.99 & -2.21 \\
\hline
\end{tabular}

electrons in the excited state. For (13), to reach high $J_{\mathrm{sc}}$, the DSSCs should have a large $\Delta G_{\text {inject }}$ that is computed by [64]

$$
\Delta G_{\text {inject }}=E_{\mathrm{ox}}^{\mathrm{dye}^{*}}-E_{\mathrm{CB}}^{\mathrm{TiO}_{2}} .
$$

Here, $E_{\text {ox }}^{\text {dye }^{*}}$ is the oxidation potential of excited dye and $E_{\mathrm{CB}}^{\mathrm{TiO}_{2}}$ is the reduction potential of conduction band $\mathrm{TiO}_{2}\left(E_{\mathrm{CB}}^{\mathrm{TiO}_{2}}=4.0 \mathrm{eV}\right)$ and $E_{\mathrm{ox}}^{\text {dye* }}$ can be calculated as [65]:

$$
E_{\mathrm{ox}}^{\mathrm{dye}^{*}}=E_{\mathrm{ox}}^{\mathrm{dye}}-\Delta E,
$$

where $E_{\mathrm{ox}}^{\mathrm{dye}}$ is the oxidation potential of the dye in the ground state and $\Delta E$ is an experiment electronic vertical energy related to $\lambda_{\max }$.

The data of Tetrabromophenol blue and Bromoxylenol blue are listed in Table 2. The absolute value of $\Delta G_{\text {inject }}$ of Tetrabromophenol blue is $2.25 \mathrm{eV}$, which is larger than that of Bromoxylenol blue (2.21). LHE of Tetrabromophenol blue and Bromoxylenol blue are 0.0284 and 0.0290 , respectively. According to (13), $\Delta G_{\text {inject }}$ of Tetrabromophenol blue is bigger than that of Bromoxylenol blue, which is helpful to improve the $J_{\text {sc }}$ ability for Tetrabromophenol blue.

3.8. Natural Bond Orbital Analysis. Natural bond orbital (NBO) exploits the second-order Fock matrix to get the donor-acceptor interactions [66]. For the sake of illuminating intramolecular rehybridization and delocalization of electron density within the molecule, NBO analyses of Tetrabromophenol blue and Bromoxylenol blue are calculated and the information is listed in Table S4 and Table S5. As shown, $\mathrm{E}(2)$ means that the energy of hyper conjugative interaction (stabilization energy)) has higher value and electron donors and electron acceptors have stronger interaction and larger extent of conjugation of the entire system.

Stabilization is caused by intramolecular hyperconjugative interaction of molecules. Intramolecular hyperconjugative interaction of $\pi^{*}$ (C17-C18) distributed to $\pi^{*}$ (C16C21) leads to the strongest stabilization of $285.88 \mathrm{KJ} / \mathrm{mol}$ (for Tetrabromophenol blue). The strong intramolecular hyperconjugative interaction of $\pi^{*}$ (C14-C15), $\pi^{*}$ (C5-C6), $\pi^{*}$ (C19-C20), and $\pi^{*}$ (C1-C2) distributes to $\pi^{*}$ (C10-C11), $\pi^{*}$ (C3-C4), $\pi^{*}$ (C21-C22), and $\pi^{*}$ (C3-C4), and E(2) values are $269.58 \mathrm{KJ} / \mathrm{mol}, \quad 152.56 \mathrm{KJ} / \mathrm{mol}, \quad 181.99 \mathrm{KJ} / \mathrm{mol}$, and $160.11 \mathrm{KJ} / \mathrm{mol}$ (see Table S4). For Bromoxylenol blue, the electron delocalization is distributed form donor to acceptor that are $\pi^{*} \rightarrow \pi^{*}$ and they are C18-C19 $\rightarrow$ C20$\mathrm{C} 21(278.95 \mathrm{KJ} / \mathrm{mol}), \mathrm{C} 18-\mathrm{C} 19 \rightarrow \mathrm{C} 10-\mathrm{C} 11(271.65 \mathrm{KJ} / \mathrm{mol})$, $\mathrm{C} 12-\mathrm{C} 14 \rightarrow \mathrm{C} 15-\mathrm{C} 16 \quad(246.97 \mathrm{KJ} / \mathrm{mol}), \quad \mathrm{C} 12-\mathrm{C} 14 \rightarrow \mathrm{C} 13-$ $\mathrm{C} 17(271.69 \mathrm{KJ} / \mathrm{mol})$, and $\mathrm{C} 1-\mathrm{C} 2 \rightarrow \mathrm{C} 3-\mathrm{C} 4(176.83 \mathrm{KJ} / \mathrm{mol})$ (see Table S5). The above results show that intramolecular
TABLE 3: Calculated molecular reorganization energies $(\mathrm{eV})$ and coupling matrix element $(\mathrm{eV})$ of Tetrabromophenol blue and Bromoxylenol blue.

\begin{tabular}{lccc}
\hline Dye & $\lambda_{h}$ & $\lambda_{e}$ & V \\
\hline Tetrabromophenol blue & 0.27 & 0.82 & 0.03 \\
Bromoxylenol blue & 0.27 & 0.54 & 0.004 \\
\hline
\end{tabular}

hyperconjugative interaction of Tetrabromophenol blue is higher than that of Bromoxylenol blue.

3.9. Mobility Calculation. The mobility as an important factor that can affect the performance of DSSC, and it is computed to provide the calculation of value for applications of organics in electronic devices. So, the drift mobility of hopping $(\mu)$ is expressed [67]:

$$
\mu=\frac{e}{2 n k_{B} T} \sum_{i} r^{2} W_{i} P_{i}
$$

where $n=3$ is the dimensionality, $e$ is the electronic charge, $k_{\mathrm{B}}$ is the Boltzmann constant, $T$ is the temperature, $r$ is the distance of the center of mass, and $P$ is the relative probability for charge carrier to a particular $i$ th neighbor

$$
P_{i}=\frac{W_{i}}{\sum_{i} W_{i}}
$$

According to the standard Marcus theory, $W_{i}$ can be compared by the rate of charge motion between neighboring molecules and it is obtained by the reorganization energy $\lambda$ and the coupling matrix element $\mathbf{V}$ and it can be written as [68]

$$
W_{i}=\frac{\mathbf{V}^{2}}{\hbar}\left(\frac{\pi}{\lambda k_{B} T}\right)^{1 / 2} \exp \left(-\frac{\lambda}{4 k_{B} T}\right) .
$$

where $\mathbf{V}$ and $\lambda$ play important roles for $W_{i}$ and they are achieved by framework of the Marcus-Hush theory. $\mathbf{V}$ is closely correlated with $E_{\mathrm{HOMO}}$ and $E_{\mathrm{HOMO}-1}$, and $\lambda$ is divided into hole reorganization energy $\left(\lambda_{e}\right)$ and electron reorganization energy $\left(\lambda_{h}\right)$. So, $\mathbf{V}, \lambda_{e}$, and $\lambda_{h}$ are expressed [69]:

$$
\begin{aligned}
& \mathbf{V}=\frac{1}{2}\left(E_{\mathrm{HOMO}}-E_{\mathrm{HOMO}-1}\right), \\
& \lambda_{h}=\left(E_{0}^{*}-E_{0}\right)+\left(E_{+}^{*}-E_{+}\right), \\
& \lambda_{e}=\left(E_{0}^{*}-E_{0}\right)+\left(E_{-}^{*}-E_{-}\right),
\end{aligned}
$$

where $E_{+}^{*}\left(E_{-}^{*}\right)$ represents the cationic (anionic) state with the geometry of the neutral species; $E_{+}$and $E_{-}$represent the energies of the cationic and anionic with the structure of cationic and anionic species; and $E_{0}$ and $E_{0}^{*}$ represent the energies of neutral species and state, respectively. The data of $\mathbf{V}, \lambda_{e}$, and $\lambda_{h}$ are listed in Table $3 . \mathbf{V}, \lambda_{e}$, and $\lambda_{h}$ of Tetrabromophenol blue are $0.03 \mathrm{eV}, 0.82 \mathrm{eV}$, and $0.27 \mathrm{eV}$, respectively, and those of Bromoxylenol blue are $0.004 \mathrm{eV}, 0.54 \mathrm{eV}$, and $0.27 \mathrm{eV}$, respectively. According to the Marcus theory, $\mathbf{V}$ and $\lambda$ of dyes are higher and lower, which get larger $\mu$. 
TABLe 4: The calculated ionization energy $(\mathrm{eV})$, electron affinity $(\mathrm{eV})$, electronegativity $(\mathrm{eV})$, hardness $(\mathrm{eV})$, softness $\left(\mathrm{eV}^{-1}\right)$, electrophilicity index, and total molecular energies (Hartree) for the Tetrabromophenol blue and Bromoxylenol blue with the 6-31G(d) basis set.

\begin{tabular}{lccccccccc}
\hline Dye & & $I$ & $A$ & $\chi$ & $\eta$ & $S$ & $\Delta E$ & $E_{\text {TOTAL }}$ & $\varphi$ \\
\hline \multirow{2}{*}{ Tetrabromophenol blue } & Gas & 6.69 & 2.17 & 4.430 & 2.260 & 1.480 & 4.52 & -22075.48 & 4.323 \\
& Solvent & 6.64 & 2.10 & 4.370 & 2.270 & 1.463 & 4.54 & -22075.50 & 4.206 \\
Bromoxylenol Blue & Gas & 6.20 & 1.32 & 3.760 & 2.440 & 1.207 & 4.88 & -6806.13 & 2.897 \\
& Solvent & 6.27 & 1.29 & 3.780 & 2.490 & 1.259 & 4.98 & -6806.15 & 2.869 \\
\hline
\end{tabular}

$\Delta E=E_{\mathrm{HOMO}}-E_{\mathrm{LUMO}} ; I=-E_{\mathrm{HOMO}} ; A=-E_{\mathrm{LUMO}} ; \chi=(I+A) / 2 ; \eta=(I-A) / 2 ; \mathrm{S}=I / 2 \eta ; \varphi=\chi^{2} / 2 \eta$.

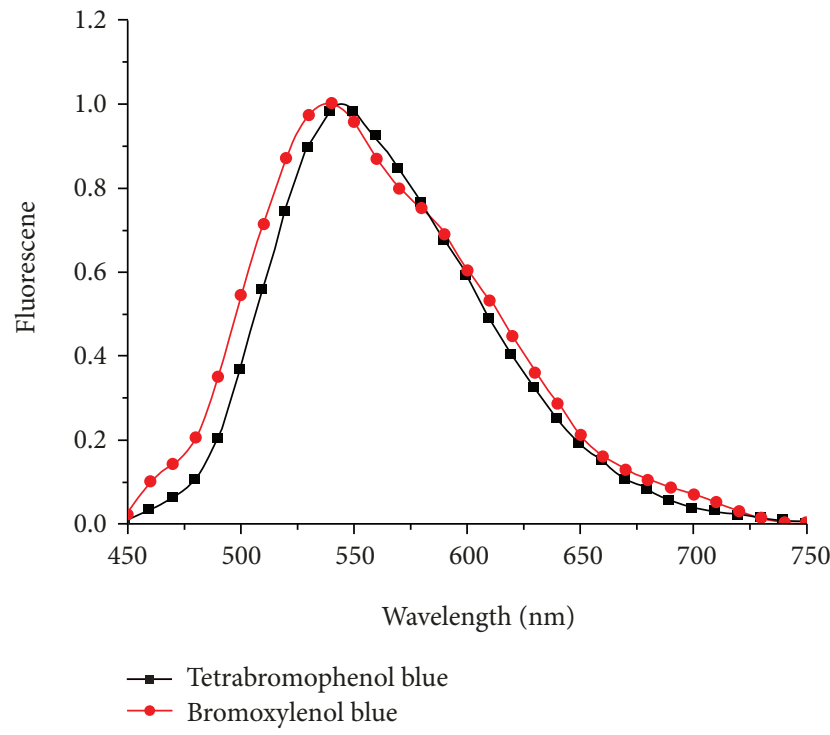

(a)

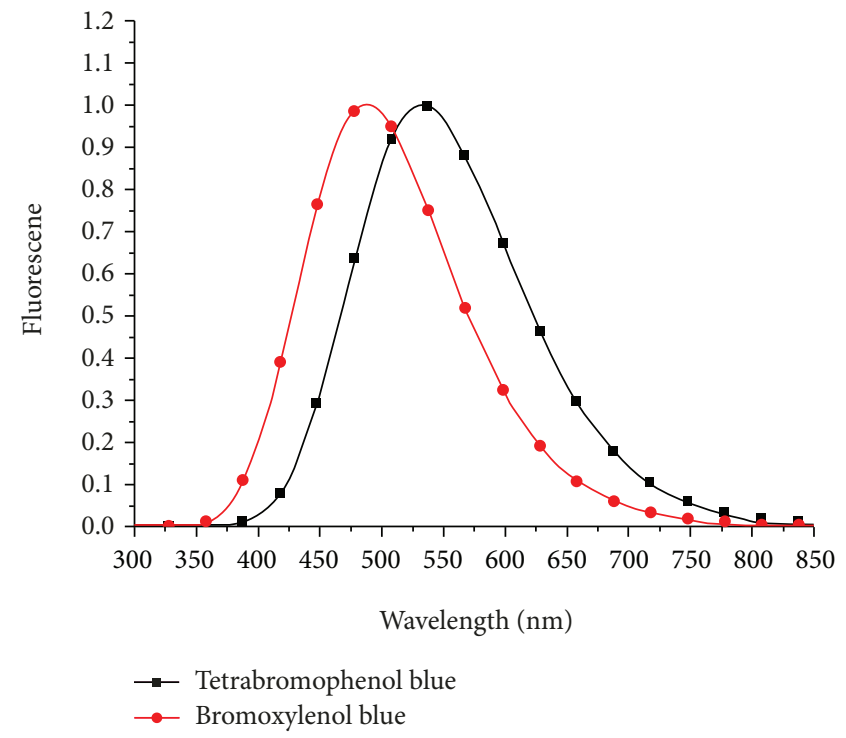

(b)

Figure 9: The experimental (a) and theoretical (b) fluorescence spectra of Tetrabromophenol blue and Bromoxylenol blue.

TABLE 5: Experimental absorption peaks, calculated transition properties, and excited-state lifetime of Tetrabromophenol blue and Bromoxylenol blue.

\begin{tabular}{|c|c|c|c|c|c|}
\hline Dye & $E(\mathrm{eV})$ & $\lambda(\mathrm{nm})$ & Strength $f$ & $T(\mathrm{~s})$ & $\operatorname{Exp}(\mathrm{nm})$ \\
\hline Tetrabromophenol blue & 1.28 & 537 & 0.0066 & $2.16 \times 10^{-5}$ & 548 \\
\hline Bromoxylenol blue & 2.33 & 533 & 0.0087 & $4.90 \times 10^{-7}$ & 540 \\
\hline
\end{tabular}

3.10. Molecular Descriptors. The electron affinity $(A)$ and ionization potential $(I)$ can affect the energy barrier of electrons. The data of the energy barrier between HOMO level and LUMO level are $-4.52 \mathrm{eV}$ and $-4.54 \mathrm{eV}$ in gas and solvent, respectively, (for Tetrabromophenol blue) and those of Bromoxylenol blue are $-4.88 \mathrm{eV}$ and $-4.98 \mathrm{eV}$, respectively (see Table 4). So, the absolute value of the energy barrier of Tetrabromophenol blue is lower than that of Bromoxylenol blue. Moreover, the total and FMO energies $\left(E_{\text {TOTAL }}\right)$, electronegativity $(\chi)$, chemical hardness $(\eta)$, and chemical softness (S) are computed by $6-31 \mathrm{G}(\mathrm{d})$ in gas and solvent. Parr et al. found that the lower $\eta$ results in the lower resistance to intramolecular charge transfer [70]. $\eta$ values of Tetrabromophenol blue $(2.260 \mathrm{eV}$ and $2.270 \mathrm{eV})$ are lower than those of Bromoxylenol blue $(2.440 \mathrm{eV}$ and $2.490 \mathrm{eV})$. The chemical hardness is an important factor, which is a measure of resistance to charger transfer.
3.11. Fluorescence Spectroscopy of Dyes. Excited-state lifetime $(\tau)$ plays an important role in DSSCs, and it can affect the efficiency of charge transfer. The longer $\tau$ can keep the dye in the cationic form for a long time, which can be expressed as [71]:

$$
\tau=\frac{a c^{3} u^{2}}{2 f e^{2}}
$$

where $c$ is the speed of light, $f$ is the oscillator strength, $e$ is the fluorescent energy, and $u$ is a constant. Figure 9 shows the experimental spectra and academic spectra; the fluorescence maxima $\lambda$, oscillator strength ( $f$ in $\mathrm{au}$ ), and $\tau$ are listed in Table 5. For experiment and computational work, the maximum absorption peaks of Tetrabromophenol blue are $548 \mathrm{~nm}$ and $537 \mathrm{~nm}$, respectively, and those of Bromoxylenol blue are $540 \mathrm{~nm}$ and $533 \mathrm{~nm}$, respectively, and the 
fluorescence energy, $f$, and $\tau$ are $1.28 \mathrm{eV}, 0.0066$, and $2.16 \times 10^{-5} \mathrm{~s}$, respectively. While, for Bromoxylenol blue, the fluorescence energy, $f$, and $\tau$ are $2.33 \mathrm{eV}, 0.0087$, and $4.90 \times 10^{-7}$, respectively. Those results showed that $\tau$ of Tetrabromophenol blue is higher, which means that Tetrabromophenol blue can remain stable in the cationic stat for a long time.

\section{Conclusion}

The photoelectrical properties of Tetrabromophenol blue and Bromoxylenol blue as the sensitizers of DSSCs are measured in experiments. The absorption and fluorescence spectra, frontier molecular orbital, energy gaps, electronic structures, and MEP of Tetrabromophenol blue and Bromoxylenol blue are computed via DFT and TDDFT methods. As the key parameters (excited-state lifetime $(\tau)$, the driving force of electron injection $\left(\Delta G_{\text {inject }}\right)$, and the vertical dipole moment $\left.\left(\mu_{\text {normal }}\right)\right)$, they have a close connection with $J_{\text {sc }}$ and $V_{\text {oc }} \cdot \tau\left(2.16 \times 10^{-5} \mathrm{~s}\right)$, absolute value of $\Delta G_{\text {inject }}$ $(2.25 \mathrm{eV})$, and absolute value of $\mu_{\text {normal }}(1.3838 \mathrm{D})$ of Tetrabromophenol blue are larger than those of Bromoxylenol blue. $J_{\mathrm{sc}}$ and $V_{\mathrm{oc}}$ of Tetrabromophenol blue are $0.39 \mathrm{~V}$ and $0.09 \mathrm{~mA} / \mathrm{cm}^{2}$, respectively, which are higher than those of Bromoxylenol blue. The results show that the larger $\tau, \Delta G_{\text {inject }}$, and $\mu_{\text {normal }}$ can be in favor of improving the values of $J_{\mathrm{sc}}$ and $V_{\mathrm{oc}}$. Therefore, the photovoltaic performance of Tetrabromophenol blue is significantly better than that of Bromoxylenol blue.

\section{Data Availability}

The data used to support the findings of this study are available from the corresponding author upon request.

\section{Conflicts of Interest}

The authors declare no conflict of interest.

\section{Acknowledgments}

This work was supported by the National Natural Science Foundation of China (Grant nos. 11404055 and 61675165), the Postdoctoral Foundation of Heilongjiang Province Grant (LBH-Z15002), and China Postdoctoral Science Foundation (2016M590270).

\section{Supplementary Materials}

Calculated transition energy and oscillator strength in various methods (see Table S1); energy levels of HOMO and LUMO and energy gap (eV) (see Table S2); Table S3: current-voltage characteristics of Tetrabromophenol blue and Bromoxylenol blue; Table S4: second-order perturbation computational work analysis of Fock matrix in natural bond orbital for Tetrabromophenol blue; Table S5: second-order perturbation computational work analysis of Fock matrix in natural bond orbital for Bromoxylenol blue. (Supplementary Materials)

\section{References}

[1] R. L. Milot and C. A. Schmuttenmaer, "Electron injection dynamics in high-potential porphyrin photoanodes," Accounts of Chemical Research, vol. 48, no. 5, pp. 1423-1431, 2015.

[2] D. Schmidt, M. D. Hager, and U. S. Schubert, "Photorechargeable electric energy storage systems," Advanced Energy Materials, vol. 6, no. 1, article 1500369, 2016.

[3] L. J. Brennan, M. T. Byrne, M. Bari, and Y. K. Gun'ko, "Carbon nanomaterials for dye-sensitized solar cell applications: a bright future," Advanced Energy Materials, vol. 1, no. 4, pp. $472-485,2011$.

[4] S. Sharma, B. Siwach, S. K. Ghoshal, and D. Mohan, "Dye sensitized solar cells: from genesis to recent drifts," Renewable and Sustainable Energy Reviews, vol. 70, pp. 529-537, 2017.

[5] N. Kaneza, J. Zhang, H. Liu et al., "Electrochemical and spectroscopic properties of boron dipyrromethene-thiophene-triphenylamine-based dyes for dye-sensitized solar cells," The Journal of Physical Chemistry C, vol. 120, no. 17, pp. 9068-9080, 2016.

[6] M. A. M. Al-Alwani, A. B. Mohamad, N. A. Ludin, A. A. H. Kadhum, and K. Sopian, "Dye-sensitised solar cells: development, structure, operation principles, electron kinetics, characterisation, synthesis materials and natural photosensitisers," Renewable and Sustainable Energy Reviews, vol. 65, pp. 183-213, 2016.

[7] Y. He, P. Xu, B. Zhang et al., "Ultrasmall $\mathrm{MnO}$ nanoparticles supported on nitrogen-doped carbon nanotubes as efficient anode materials for sodium ion batteries," ACS Applied Materials \& Interfaces, vol. 9, no. 44, pp. 38401-38408, 2017.

[8] G. Wang, Z. Liu, Y. Deng, L. Xie, and S. Tan, "Comparative study on N,N-di-p-tolylaniline-based $\mathrm{D}-\pi$-A1- $\pi$-A2 sensitizers by tuning the auxiliary acceptor for dye-sensitized solar cells," Dyes and Pigments, vol. 145, pp. 427-435, 2017.

[9] Tanvi, V. Saxena, A. Singh et al., "Improved performance of dye sensitized solar cell via fine tuning of ultra-thin compact $\mathrm{TiO}_{2}$ layer," Solar Energy Materials and Solar Cells, vol. 170, pp. 127-136, 2017.

[10] S. Kushwaha, M. P. Karthikayini, G. Wang et al., "A nonplatinum counter electrode, $\mathrm{MnN}_{\mathrm{x}} / \mathrm{C}$, for dye-sensitized solar cell applications," Applied Surface Science, vol. 418, pp. 179-185, 2017.

[11] M. S. Ahmad, A. K. Pandey, and N. Abd Rahim, "Advancements in the development of $\mathrm{TiO}_{2}$ photoanodes and its fabrication methods for dye sensitized solar cell (DSSC) applications. A review," Renewable \& Sustainable Energy Reviews, vol. 77, pp. 89-108, 2017.

[12] P. Li, Y. Zhang, W. Fa, X. Yang, and L. Wang, "Hollow platinum alloy tailored counter electrodes for photovoltaic applications," Journal of Power Sources, vol. 360, pp. 232-242, 2017.

[13] B. O’Regan and M. Grätzel, "A low-cost, high-efficiency solar cell based on dye-sensitized colloidal $\mathrm{TiO}_{2}$ films," Nature, vol. 353, no. 6346, pp. 737-740, 1991.

[14] A. Sasani, A. Baktash, K. Mirabbaszadeh, and B. Khoshnevisan, "Structural and electronic properties of $\mathrm{Mg}$ and $\mathrm{Mg}-\mathrm{Nb}$ codoped TiO2 (101) anatase surface," Applied Surface Science, vol. 384, pp. 298-303, 2016.

[15] M. Magni, P. Biagini, A. Colombo, C. Dragonetti, D. Roberto, and A. Valore, "Versatile copper complexes as a convenient springboard for both dyes and redox mediators in dye 
sensitized solar cells," Coordination Chemistry Reviews, vol. 322, pp. 69-93, 2016.

[16] J. Jaksik, H. J. Moore, T. Trad, O. I. Okoli, and M. J. Uddin, "Nanostructured functional materials for advanced threedimensional (3D) solar cells," Solar Energy Materials and Solar Cells, vol. 167, pp. 121-132, 2017.

[17] C. A. Ubani, M. A. Ibrahim, and M. A. M. Teridi, "Moving into the domain of perovskite sensitized solar cell," Renewable and Sustainable Energy Reviews, vol. 72, pp. 907-915, 2017.

[18] H. Tsai, W. Nie, J.-C. Blancon et al., "High-efficiency twodimensional Ruddlesden-Popper perovskite solar cells," Nature, vol. 536, no. 7616, pp. 312-316, 2016.

[19] S. Hao, Y. Shang, D. Li, H. Ågren, C. Yang, and G. Chen, "Enhancing dye-sensitized solar cell efficiency through broadband near-infrared upconverting nanoparticles," Nanoscale, vol. 9, no. 20, pp. 6711-6715, 2017.

[20] M. Gratzel, "The light and shade of perovskite solar cells," Nature Materials, vol. 13, no. 9, pp. 838-842, 2014.

[21] G. Gorni, I. Zama, S. Vierucci, C. Martelli, and L. Armiento, "A scalable monitoring method of dye uptake in dyesensitized solar cells and modules: optimization of Z907 impregnation time for long term stability," Solar Energy, vol. 150, pp. 83-89, 2017.

[22] I. A. Sahito, K. C. Sun, W. Lee, J. P. Kim, and S. H. Jeong, "Graphene nanosheets as counter electrode with phenoxazine dye for efficient dye sensitized solar cell," Organic Electronics, vol. 44, pp. 32-41, 2017.

[23] Y. H. Chiu, M. Shibahara, R. Y. Huang et al., "Triphenylamine derivatives and the lithium-ion capture of [3.3]cyclophane used in organic dye-sensitized solar cells," Dyes and Pigments, vol. 136, pp. 761-772, 2017.

[24] M. Z. H. Khan, M. R. Al-Mamun, P. K. Halder, and M. A. Aziz, "Performance improvement of modified dye-sensitized solar cells," Renewable and Sustainable Energy Reviews, vol. 71, pp. 602-617, 2017.

[25] C. K. Kim, I. T. Choi, S. H. Kang, and H. K. Kim, "Anchovyderived nitrogen and sulfur co-doped porous carbon materials for high-performance supercapacitors and dye-sensitized solar cells," RSC Advances, vol. 7, no. 57, pp. 35565-35574, 2017.

[26] K. Stalindurai, A. Karuppasamy, J. D. Peng, K. C. Ho, and C. Ramalingan, "Azafluorene ornamented thiazine based novel fused heterocyclic organic dyes for competent molecular photovoltaics," Electrochimica Acta, vol. 246, pp. 1052-1064, 2017.

[27] T. B. Raju, J. V. Vaghasiya, M. A. Afroz, S. S. Soni, and P. K. Iyer, "Design, synthesis and DSSC performance of $o$-fluorine substituted phenylene spacer sensitizers: effect of $\mathrm{TiO}_{2}$ thickness variation," Physical Chemistry Chemical Physics, vol. 18, no. 41, pp. 28485-28491, 2016.

[28] T. S. Raju, J. V. Vaghasiya, M. A. Afroz, S. S. Soni, and P. K. Iyer, "Influence of $m$-fluorine substituted phenylene spacer dyes in dye-sensitized solar cells," Organic Electronics, vol. 39, pp. 371-379, 2016.

[29] J. H. Huang, P. H. Lin, W. M. Li, K. M. Lee, and C. Y. Liu, "Sn- and Pd-free synthesis of D- $\pi$-A organic sensitizers for dye-sensitized solar cells by $\mathrm{Cu}$-catalyzed direct arylation," ChemSusChem, vol. 10, no. 10, pp. 2284-2290, 2017.

[30] A. Alagumalai, M. K. M. Fairoos, P. Vellimalai, M. C. Sil, and J. Nithyanandhan, "Effect of out-of-plane alkyl group's position in dye-sensitized solar cell efficiency: a structure-property relationship utilizing Indoline-based unsymmetrical squaraine dyes," ACS Applied Materials \& Interfaces, vol. 8, no. 51, pp. 35353-35367, 2016.

[31] L.-W. Ma, Z.-S. Huang, S. Wang, H. Meier, and D. Cao, "Impact of $\pi$-conjugation configurations on the photovoltaic performance of the quinoxaline-based organic dyes," Dyes and Pigments, vol. 145, pp. 126-135, 2017.

[32] M. Freitag, J. Teuscher, Y. Saygili et al., "Dye-sensitized solar cells for efficient power generation under ambient lighting," Nature Photonics, vol. 11, no. 6, pp. 372-378, 2017.

[33] Y. Li, C. Sun, P. Song, F. Ma, and Y. Yang, "Tuning the electron-transport and electron-accepting abilities of dyes through introduction of different $\pi$-conjugated bridges and acceptors for dye-sensitized solar cells," ChemPhysChem, vol. 18, no. 4, pp. 366-383, 2017.

[34] L. J. He, J. Wang, J. Chen, R. Jia, and H. X. Zhang, “The effect of relative position of the $\pi$-spacer center between donor and acceptor on the overall performance of $\mathrm{D}-\pi$-A dye: a theoretical study with organic dye," Electrochimica Acta, vol. 241, pp. 440-448, 2017.

[35] P. Ren, Y. Zhang, Z. Luo, P. Song, and Y. Li, "Theoretical and experimental study on spectra, electronic structure and photoelectric properties of three nature dyes used for solar cells," Journal of Molecular Liquids, vol. 247, pp. 193-206, 2017.

[36] B. A. Ali and N. K. Allam, "Propping the optical and electronic properties of potential photo-sensitizers with different $\pi$-spacers: TD-DFT insights," Spectrochimica Acta Part A: Molecular and Biomolecular Spectroscopy., vol. 188, pp. 237-243, 2018.

[37] W. S. W. Sharmoukh, W. M. I. Hassan, P. C. Gros, and N. K. Allam, "Design and synthesis of new Ru-complexes as potential photo-sensitizers: experimental and TD-DFT insights," RSC Advances, vol. 6, no. 73, pp. 69647-69657, 2016.

[38] R. M. El-Shishtawy, S. A. Elroby, A. M. Asiri, and K. Müllen, "Optical absorption spectra and electronic properties of symmetric and asymmetric squaraine dyes for use in DSSC solar cells: DFT and TD-DFT studies," International Journal of Molecular Sciences, vol. 17, no. 4, p. 487, 2016.

[39] C. Lee, W. Yang, and R. G. Parr, "Development of the Colle-Salvetti correlation-energy formula into a functional of the electron density," Physical Review B, vol. 37, no. 2, pp. 785-789, 1988.

[40] D. Casanova, F. P. Rotzinger, and M. Grätzel, “Computational study of promising organic dyes for high-performance sensitized solar cells," Journal of Chemical Theory and Computation, vol. 6, no. 4, pp. 1219-1227, 2010.

[41] X. Zarate, S. Schott-Verdugo, A. Rodriguez-Serrano, and E. Schott, "The nature of the donor motif in acceptor-bridgedonor dyes as an influence in the electron photo-injection mechanism in DSSCs," The Journal of Physical Chemistry A, vol. 120, no. 9, pp. 1613-1624, 2016.

[42] F. Schoenebeck, D. H. Ess, G. O. Jones, and K. N. Houk, "Reactivity and regioselectivity in 1,3-dipolar cycloadditions of azides to strained alkynes and alkenes: a computational study," Journal of the American Chemical Society, vol. 131, no. 23, pp. 8121-8133, 2009.

[43] T. Yanai, D. P. Tew, and N. C. Handy, "A new hybrid exchange-correlation functional using the Coulombattenuating method (CAM-B3LYP)," Chemical Physics Letters, vol. 393, no. 1-3, pp. 51-57, 2004.

[44] S. Huang, J. Zai, D. Ma et al., "Improving the catalytic performance of $\mathrm{Ni}_{3} \mathrm{~S}_{4}$-PtCo heteronanorods via Mott-Schottky 
effect toward the reduction of iodine couples in dyesensitized solar cells," Electrochimica Acta, vol. 241, pp. 89-97, 2017.

[45] R. Maragani, R. Misra, M. S. Roy, M. K. Singh, and G. D. Sharma, "(D- $\pi-A) 2-\pi-D-A$ type ferrocenyl bisthiazole linked triphenylamine based molecular systems for DSSC: synthesis, experimental and theoretical performance studies," Physical Chemistry Chemical Physics, vol. 19, no. 13, pp. 8925-8933, 2017.

[46] Y. Wen, W. Wu, Y. Li et al., "First principles study of thieno[2,3-b]indole-based organic dyes for dye-sensitized solar cells: screen novel $\pi$-linkers and explore the interface between photosensitizers and $\mathrm{TiO}_{2}$," Journal of Power Sources, vol. 326, pp. 193-202, 2016.

[47] Y. Farre, M. Raissi, A. Fihey et al., "A blue diketopyrrolopyrrole sensitizer with high efficiency in nickel-oxide-based dye-sensitized solar cells," ChemSusChem, vol. 10, no. 12, pp. 2618-2625, 2017.

[48] N. R. Sheela, S. Muthu, and S. Sampathkrishnan, "Molecular orbital studies (hardness, chemical potential and electrophilicity), vibrational investigation and theoretical NBO analysis of 4-4'-(1H-1,2,4-triazol-1-yl methylene) dibenzonitrile based on abinitio and DFT methods," Spectrochimica Acta Part A: Molecular and Biomolecular Spectroscopy, vol. 120, pp. 237-251, 2014.

[49] D. A. Kleinman, "Nonlinear dielectric polarization in optical media," Physical Review, vol. 126, no. 6, pp. 1977-1979, 1962.

[50] M. J. Frisch, G. W. Trucks, H. B. Schlegel et al., Gaussian 09, Gaussian, Inc., Wallingford, CT, USA, 2009.

[51] T. Lu and F. Chen, "Multiwfn: a multifunctional wavefunction analyzer," Journal of Computational Chemistry, vol. 33, no. 5, pp. 580-592, 2012.

[52] E. Ramasamy and J. Lee, "Ferrocene-derivatized ordered mesoporous carbon as high performance counter electrodes for dye-sensitized solar cells," Carbon, vol. 48, no. 13, pp. 3715-3720, 2010.

[53] D. M. De Leeuw, M. M. J. Simenon, A. R. Brown, and R. E. F. Einerhand, "Stability of n-type doped conducting polymers and consequences for polymeric microelectronic devices," Synthetic Metals, vol. 87, no. 1, pp. 53-59, 1997.

[54] J. B. Asbury, Y. Q. Wang, E. Hao, H. N. Ghosh, and T. Lian, "Evidences of hot excited state electron injection from sensitizer molecules to $\mathrm{TiO}_{2}$ nanocrystalline thin films," Research on Chemical Intermediates, vol. 27, no. 4-5, pp. 393-406, 2001.

[55] M. Nakano, I. Shigemoto, S. Yamada, and K. Yamaguchi, "Size-consistent approach and density analysis of hyperpolarizability: second hyperpolarizabilities of polymeric systems with and without defects," The Journal of Chemical Physics, vol. 103, no. 10, pp. 4175-4191, 1995.

[56] H. Y. Wu, A. Chaudhari, and S. L. Lee, "Theoretical studies on nonlinear optical properties of formaldehyde oligomers by $a b$ initio and density functional theory methods," Journal of Computational Chemistry, vol. 26, no. 15, pp. 1543-1564, 2005.

[57] J. L. Sanmillan, A. Fernandez-Coello, I. Fernandez-Conejero, G. Plans, and A. Gabarros, "Functional approach using intraoperative brain mapping and neurophysiological monitoring for the surgical treatment of brain metastases in the central region," Journal of Neurosurgery, vol. 126, no. 3, pp. 698-707, 2017.

[58] P. D. Thirumala, D. J. Crammond, Y. K. Loke, H. L. Cheng, J. Huang, and J. R. Balzer, "Diagnostic accuracy of motor evoked potentials to detect neurological deficit during idiopathic scoliosis correction: a systematic review," Journal of Neurosurgery: Spine, vol. 26, no. 3, pp. 374-383, 2017.

[59] S. Kushwaha and L. Bahadur, "Enhancement of power conversion efficiency of dye-sensitized solar cells by co-sensitization of Phloxine $\mathrm{B}$ and Bromophenol blue dyes on $\mathrm{ZnO}$ photoanode," Journal of Luminescence, vol. 161, pp. 426-430, 2015.

[60] I. Y. Jeon, H. M. Kim, D. H. Kweon et al., "Metalloid telluriumdoped graphene nanoplatelets as ultimately stable electrocatalysts for cobalt reduction reaction in dye-sensitized solar cells," Nano Energy, vol. 30, pp. 867-876, 2016.

[61] Z. Ning, Y. Fu, and H. Tian, "Improvement of dye-sensitized solar cells: what we know and what we need to know," Energy \& Environmental Science, vol. 3, no. 9, p. 1170, 2010.

[62] S. N. F. Yusuf, A. D. Azzahari, V. Selvanathan, R. Yahya, M. A. Careem, and A. K. Arof, "Improvement of N-phthaloylchitosan based gel polymer electrolyte in dye-sensitized solar cells using a binary salt system," Carbohydrate Polymers, vol. 157, pp. 938-944, 2017.

[63] B. Xu, Y. Li, P. Song, F. Ma, and M. Sun, "Photoactive layer based on T-shaped benzimidazole dyes used for solar cell: from photoelectric properties to molecular design," Scientific Reports, vol. 7, article 45688, 2017.

[64] C. Bao, F. Li, J. Wang et al., "One-pot Solvothermal in situ growth of $1 \mathrm{D}$ single-crystalline $\mathrm{NiSe}$ on $\mathrm{Ni}$ foil as efficient and stable transparent conductive oxide free counter electrodes for dye-sensitized solar cells," ACS Applied Materials \& Interfaces, vol. 8, no. 48, pp. 32788-32796, 2016.

[65] M. Urbani, F. A. Sarı, M. Grätzel, M. K. Nazeeruddin, T. Torres, and M. Ince, "Effect of peripheral substitution on the performance of subphthalocyanines in DSSCs," Chemistry - An Asian Journal, vol. 11, no. 8, pp. 1223-1231, 2016.

[66] R. Meenakshi, "Spectral investigations, inhibition efficiency analysis and a TD-DFT study on tuning the light harvesting efficiency (LHE) of heterocyclic 5-nitro-1,3-benzodioxole as a photosensitizer for dye sensitized solar cells (DSSCs)," RSC Advances, vol. 6, no. 68, pp. 63690-63703, 2016.

[67] Z. Shuai, H. Geng, W. Xu, Y. Liao, and J.-M. André, "From charge transport parameters to charge mobility in organic semiconductors through multiscale simulation," Chemical Society Reviews, vol. 43, no. 8, pp. 2662-2679, 2014.

[68] N. Renaud, Y. A. Berlin, and M. A. Ratner, "Impact of a single base pair substitution on the charge transfer rate along short DNA hairpins," Proceedings of the National Academy of Sciences of the United States of America, vol. 110, no. 37, pp. 14867-14871, 2013.

[69] H. Geng, Q. Peng, L. Wang et al., "Toward quantitative prediction of charge mobility in organic semiconductors: tunneling enabled hopping model," Advanced Materials, vol. 24, no. 26, pp. 3568-3572, 2012.

[70] R. G. Parr, L. v. Szentpaly, and S. Liu, "Electrophilicity index," Journal of the American Chemical Society, vol. 121, no. 9, pp. 1922-1924, 1999.

[71] T. L. Bahers, T. Pauporté, G. Scalmani, C. Adamo, and I. Ciofini, "A TD-DFT investigation of ground and excited state properties in indoline dyes used for dye-sensitized solar cells," Physical Chemistry Chemical Physics, vol. 11, no. 47, pp. 11276-11284, 2009. 


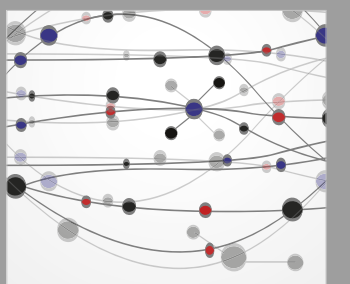

The Scientific World Journal
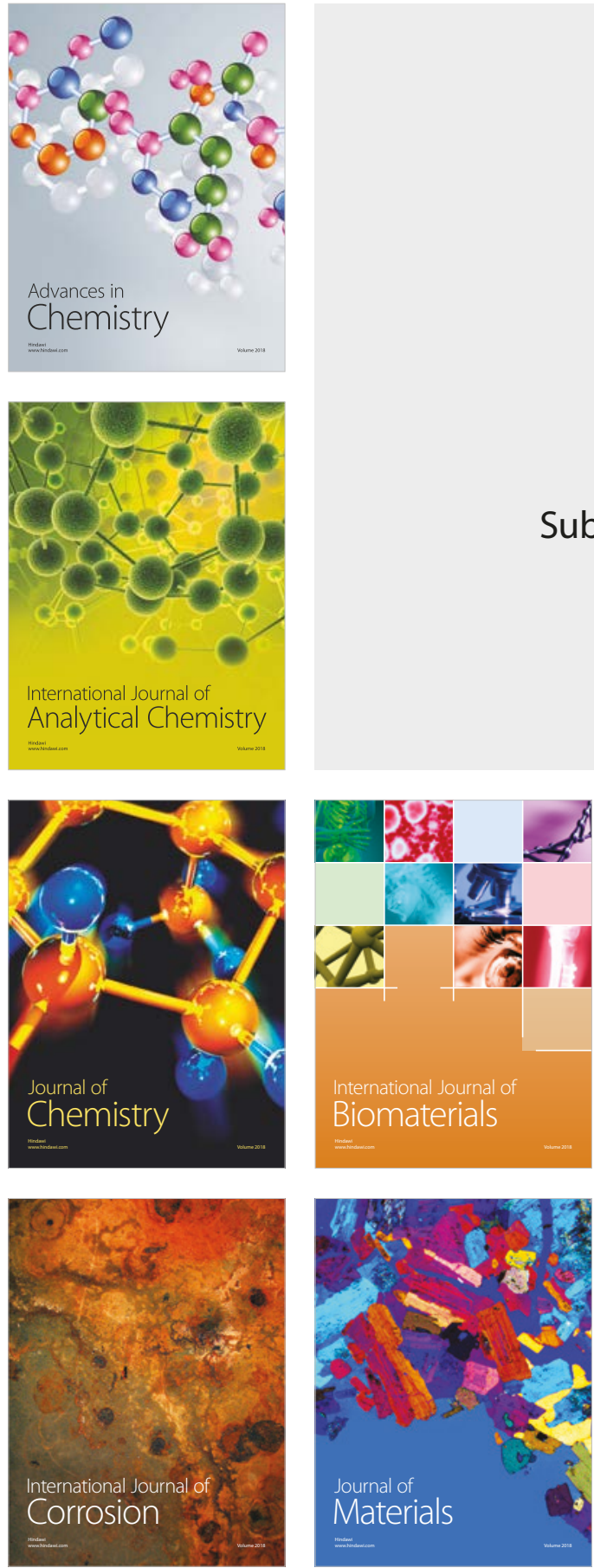

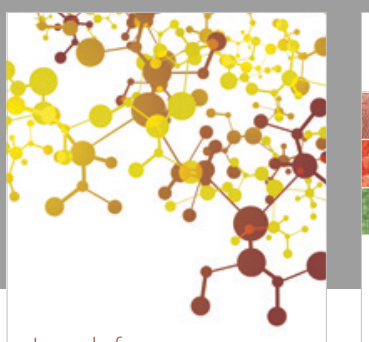

Journal of

Applied Chemistry
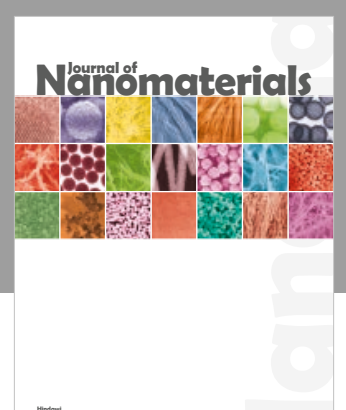

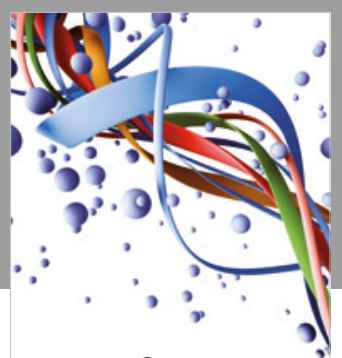

Scientifica

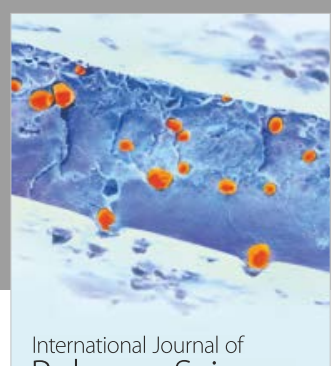

Polymer Science

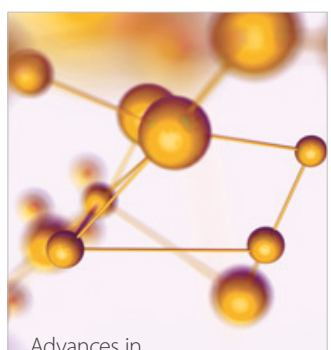

Physical Chemistry
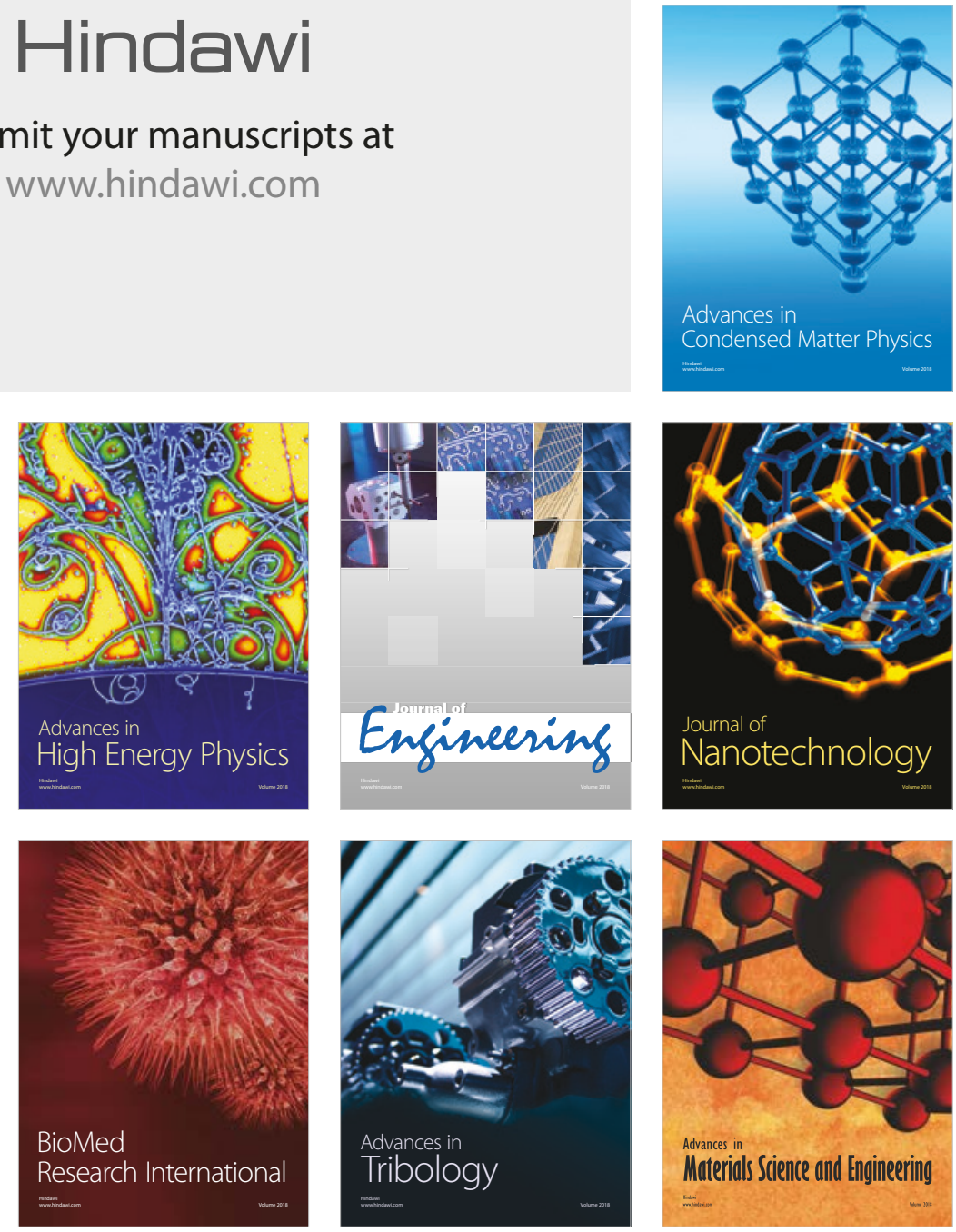